\title{
铁催化碳-碳偶联反应研究进展
}

\author{
李娟华 ${ }^{a}$ 刘昆明*,a 段新方 ${ }^{b} \quad$ 刘晋虎 $^{a}$ \\ ( ${ }^{a}$ 江西理工大学治金与化学工程学院 赣州 341000) \\ ${ }^{b}$ 北京师范大学化学学院 北京 100875$)$
}

\begin{abstract}
摘要 过渡金属催化的偶联反应是构建碳-碳键的重要手段. Fe 具有储量丰富、价廉低毒、价态多样的特点, 是一种理 想的催化剂. 随着人们对绿色、高效、高选择性反应的重视，铁催化的偶联反应研究日益增多. 特别是近 10 年来，出 现许多新的催化体系, 催生出多种反应类型, 如氧化偶联、还原偶联和 $\mathrm{C}-\mathrm{H}$ 直接官能团化. 根据偶联反应的类型, 综 述了近年来铁催化碳一碳偶联反应的研究进展. 主要介绍各反应的特点、反应机理和应用, 并展望其发展前景.
\end{abstract}

关键词 铁催化; 碳-碳偶联反应; 有机合成

\section{Recent Progress in Iron Catalyzed C-C Coupling Reactions}

\author{
Li, Juanhua $^{a} \quad$ Liu, Kunming ${ }^{*, a} \quad$ Duan, Xinfang $^{b} \quad$ Liu, Jinbiao $^{a}$ \\ ( ${ }^{a}$ School of Metallurgy and Chemical Engineering, Jiangxi University of Science and Technology, Ganzhou 341000) \\ ( ${ }^{b}$ Department of Chemistry, Beijing Normal University, Beijing 100875)
}

\begin{abstract}
Transition-metal-catalyzed coupling reactions play an important role in construct $\mathrm{C}-\mathrm{C}$ bond. As one of the most abundant metal in the earth's crust, along with its inexpensive price, relatively low toxicity and multiple redox states, Fe is an ideal catalyst for coupling reactions. Recently, green, highly effective and selective reactions have attracted much attention, which accelerated the research of iron catalyzed coupling. Particularly, many new catalyst systems and various reaction types such as iron catalyzed oxidative coupling, reductive coupling and $\mathrm{C}-\mathrm{H}$ direct functionalization were explored during the past decade. The present review surveys the recent progress in Fe catalyzed $\mathrm{C}-\mathrm{C}$ coupling concerning their reaction types, including mechanism and application. Furthermore, the prospects of this reaction are also discussed.
\end{abstract}

Keywords iron catalyzed; $\mathrm{C}-\mathrm{C}$ coupling reaction; organic synthesis

过渡金属催化的偶联反应作为一种有效的构建 碳 一碳键的手段之一, 在有机化学中占有非常重要的地位 ${ }^{[1]}$. 这些反应已被广泛地应用于药物、天然产物等复杂 化合物的合成中 ${ }^{[2]}$. 迄今为止, 大多数碳-碳偶联反应使 用的催化剂为钯或镍络合物. 尽管钯、镍催化的偶联反 应具有收率高, 底物适用范围广, 选择性高等优点 ${ }^{[3]}$, 但它们也具有以下缺点: (1)钯的价格高昂, 镍的毒性大; (2)多数情况下需特殊配体, 如膦配体或 NHC 配体等 ${ }^{[4]}$; (3)使用格氏试剂或锂试剂的反应选择性差. 这些特点 在一定程度上限制了它们在工业合成中的应用, 因此使 用其它过渡金属替代它们已成为当今过渡金属催化反 应的发展趋势之一。

铁化合物具有廉价易得、环保低毒、可呈现多种价
态等优点，是比较理想的可替代钯或镍的催化剂. 时至 今日，铁盐及其络合物 ${ }^{[5]}$ 在催化有机反应领域的应用已 有大量报道. 人们对铁催化的多种反应类型如取代、加 成、氧化、还原及不对称反应等进行了大量研究 ${ }^{[6]}$. 其 中, 对于铁催化的偶联反应, 尽管早在 20 世纪 40 年代 就有报道, 但一直未受到足够的重视. 直到 20 世纪 90 年代后期, 人们才开始重新探索此类反应. 这些研究发 现：与钯、镍催化的偶联反应相比，铁催化的偶联反应 具有一些独特的选择性 ${ }^{[7]}$, 在一些偶联反应中完全可以 代替钯、镍. 长期以来, 人们的研究主要集中于铁催化 卤代烃和金属试剂的 $\mathrm{C}\left(\mathrm{sp}^{2}\right)-\mathrm{C}\left(\mathrm{sp}^{3}\right)$ 偶联反应, 总结出 一些具有代表性的催化体 系 ${ }^{[8]}$. 近年来, 随着铁催化 碳一碳偶联反应类型的不断拓展, 出现了许多新的催化

\footnotetext{
* Corresponding author. E-mail: liukunminglkm@sina.com
}

Received August 16, 2016; revised September 22, 2016; published online October 18, 2016.

Project supported by the National Natural Science Foundation of China (Nos. 21372031, 21502075) and the Doctoral Scientific Research Foundation of Jiangxi University of Science and Technology.

国家自然科学基金(Nos. 21372031, 21502075)、江西理工大学博士启动经费资助项目. 
体系. 特别是近十年来, 铁催化的氧化偶联、还原偶联 和 $\mathrm{C}-\mathrm{H}$ 直接官能团化引起了人们的极大关注, 对铁催 化偶联的机理也进行了大量研究. 本文主要从反应类型 出发, 综述了近年来铁催化的偶联反应最新研究进展.

\section{1 铁催化卤代烃与金属试剂的偶联反应}

\section{1 铁催化的 $\mathrm{C}\left(\mathrm{sp}^{2}\right)-\mathrm{C}\left(\mathrm{sp}^{3}\right)$ 偶联反应}

\subsection{1 铁催化 $\mathrm{C}\left(\mathrm{sp}^{2}\right)-\mathrm{X}$ 与 $\mathrm{C}\left(\mathrm{sp}^{3}\right)-\mathrm{M}$ 的偶联反应}

铁催化的偶联反应最早可以追溯到 1945 年, Kharasch 等 ${ }^{[9]}$ 发现在 $\mathrm{FeCl}_{3}$ 存在下, 苯基格氏试剂和溴 苯能偶联生成联苯. 在 1971 年, $\mathrm{Kochi}^{[10]}$ 发现 $\mathrm{FeCl}_{3}$ 可催 化卤代烯烃与格氏试剂的偶联，反应具有立体选择性， 反式烯烃的反应速度远高于顺式烯烃(Scheme 1). 值得 注意的是, 与二级卤代烃的格氏试剂的反应并没有发现 明显的重排产物. 1981 年, Walborsky ${ }^{[11]}$ 的研究同样证实 了反应具有很高的立体选择性. Molander ${ }^{[12]}$ 则发现卤代 烯烃与大位阻的格氏试剂反应时, 立体选择性会下降 (Scheme 1). 这些研究尽管零散, 但充分显示铁是完全 可以催化偶联反应的. 不足的是, 这些反应都使用了过 量的卤代烯烃, 且底物的适用范围较窄, 只有碘代或溴 代烯烃能参与反应，而氯代烯烃则不能反应，此外反应 也不适用于带有敏感官能团的底物.

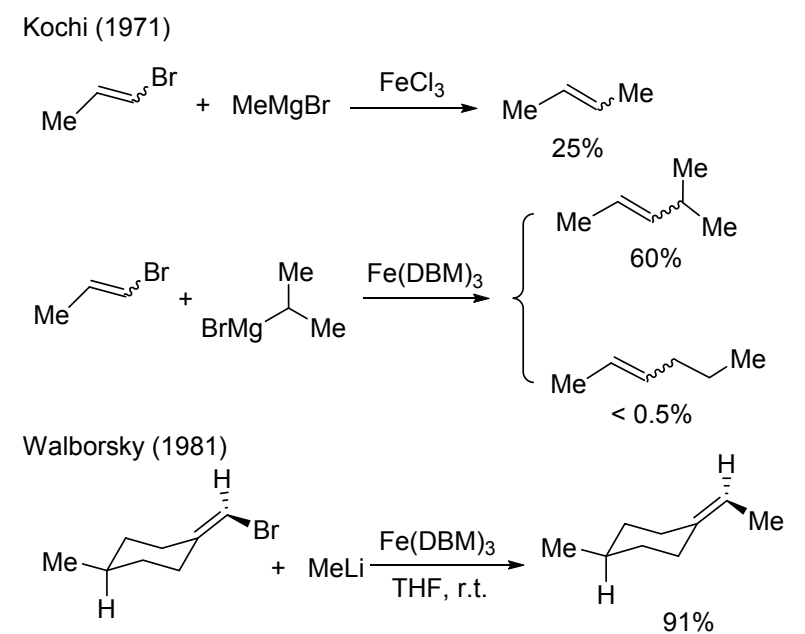

Molander (1983)
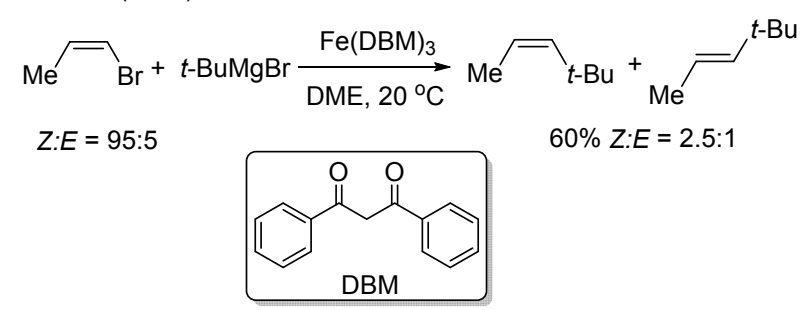

图式 1 铁催化卤代烯烃的 $\mathrm{C}\left(\mathrm{sp}^{2}\right)-\mathrm{C}\left(\mathrm{sp}^{3}\right)$ 偶联反应 Scheme 1 Iron catalyzed $\mathrm{C}\left(\mathrm{sp}^{2}\right)-\mathrm{C}\left(\mathrm{sp}^{3}\right)$ cross-coupling of alkenyl halides
遗憾的是，尽管铁催化的偶联反应很早就被发现， 但由于钯、镍催化的偶联反应研究热潮的掀起, 对铁催 化的偶联反应研究停滞了很长一段时间. 直到 20 世纪 90 年代后期, $\mathrm{Cahiez}^{[13]}$ 在四氢呋喃(THF)中加入 $N$-甲基 吡咯烷酮(NMP)作为共溶剂, 使得铁催化的碳一碳偶联 反应有了明显的改进. NMP 作为共溶剂能稳定反应中高 活性的铁中间体，这使得卤代烃用量明显减小，收率也 有了明显的改善, 且反应的适用性也更加广泛(Eq. 1).

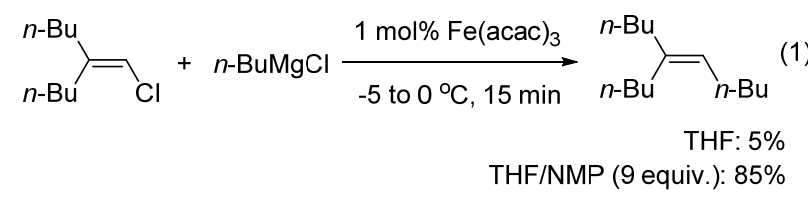

2002 年, 在 Cahiez 的研究基础上, Fürstner 等 ${ }^{[14]}$ 报 道了使用多种铁化合物如 $\mathrm{FeCl}_{n} 、 \mathrm{Fe}(\mathrm{acac})_{n}(n=2,3)$ 及 $\mathrm{Fe}$ (salen)Cl 等催化卤代(杂)芳烃和格氏试剂、锌试剂、 锰试剂的偶联反应(Scheme 2). 该反应的适用范围广, $\mathrm{Cl} 、 \mathrm{OTs} 、 \mathrm{OTf}$ 等均可作为离去基团参与反应，带吸电子 基的氯代芳烃与烷基格氏试剂反应收率很好，而澳代和 碘代芳烃在该条件下则被还原. 对于带推电子基的芳 烃, 需要使用三氟甲磺酸酯(ArOTf)才能取得良好的收 率. 该反应具有较好的官能团耐受性, 芳杂环上所带的 多种官能团，如酯基、㲵基、三氟甲基、磺酸酯、磺酰 胺等都不受影响. 对于反应的机理, 他们认为, 在反应 中铁与格氏试剂原位生成了一种 “无机格氏试剂” $\left[\mathrm{Fe}(\mathrm{MgX})_{2}\right]$, 作为催化剂参与了整个催化循环过程.

随后, Fürstner 等 ${ }^{[15]}$ 采用铁催化的方法, 先后完成了 $(R)-(+)$-muscopyridine、 Latrunculin $\mathrm{A}$ 和 Latrunculin $\mathrm{B}$ 的全合成.

在 2004 年, Fürstner 等 ${ }^{[16]}$ 使用 $\mathrm{Fe}(\mathrm{acac})_{3}$ 为催化剂, 在 THF/NMP 混合溶剂中实现了烯烃的三氟甲磺酸酯与 脂肪族格氏试剂的偶联, 这一研究成果被应用于免疫抑 制剂FTY720 的合成中 ${ }^{[17]}$ (Scheme 3). 值得注意的是, 在 研究中 Fürstner 等使用了一种铁的 ate- 络合物 $\left(\left[\mathrm{Me}_{4} \mathrm{Fe}\right] \mathrm{Li}_{2}\right)^{[18]}$, 反应结果与 $\mathrm{Fe}(\mathrm{acac})_{3}$ 相同, 这也进一步 证实了关于 “无机格氏试剂” 具有催化效果的推测.

同一时期, Hocek 等 ${ }^{[19]}$ 采用这一反应条件实现了氯 代嘌呤化合物与格氏试剂的偶联. 与钯催化的同一反应 相比, 铁催化具有区域选择性, 格氏试剂只与嘌呤的 6位氯进行偶联. 2006 年, Olsson 等 ${ }^{[20]}$ 实现了氯代亚胺化 合物和格氏试剂的偶联，并利用这一方法，制备了一系 列氯氮平类似物(Scheme 4).

\subsection{2 铁催化 $\mathrm{C}\left(\mathrm{sp}^{2}\right)-\mathrm{M}$ 与 $\mathrm{C}\left(\mathrm{sp}^{3}\right)-\mathrm{X}$ 的偶联反应}

另一方面, 尽管铁催化的卤代芳烃(烯烃)与脂肪族 格氏试剂的偶联反应已取得了很好的进展, 但这些成果 


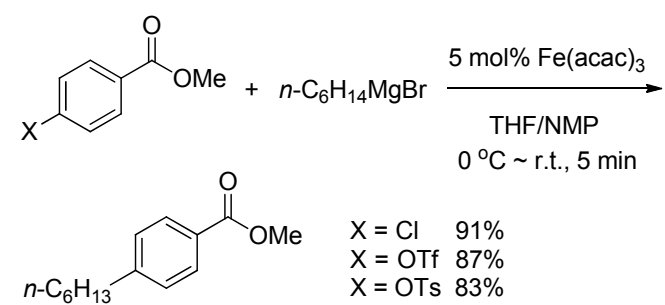

$\underset{\substack{\text { THF/NMP } \\ 0^{\circ} \mathrm{C} \sim \text { r.t., } 5 \text { min }}}{\mathrm{MgBr}} \underset{56 \%}{5 \mathrm{~mol} \% \mathrm{Fe}(\mathrm{acac})_{3}}$

隹
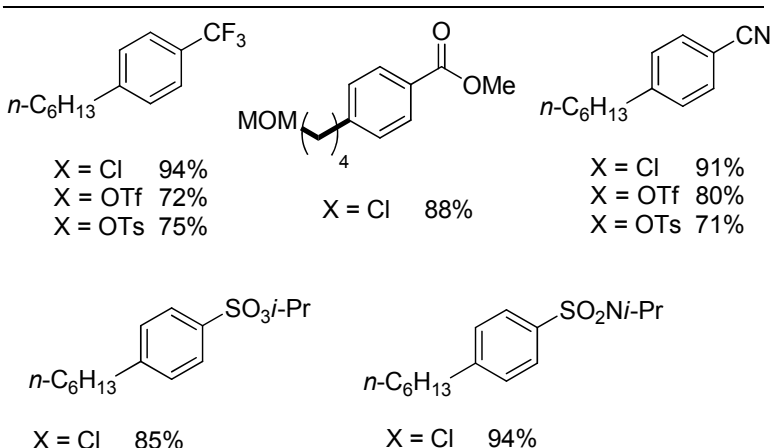

图式 2 铁催化卤代芳烃的 $\mathrm{C}\left(\mathrm{sp}^{2}\right)-\mathrm{C}\left(\mathrm{sp}^{3}\right)$ 偶联反应

Scheme 2 Iron catalyzed $\mathrm{C}\left(\mathrm{sp}^{2}\right)-\mathrm{C}\left(\mathrm{sp}^{3}\right)$ cross-coupling of aryl halides

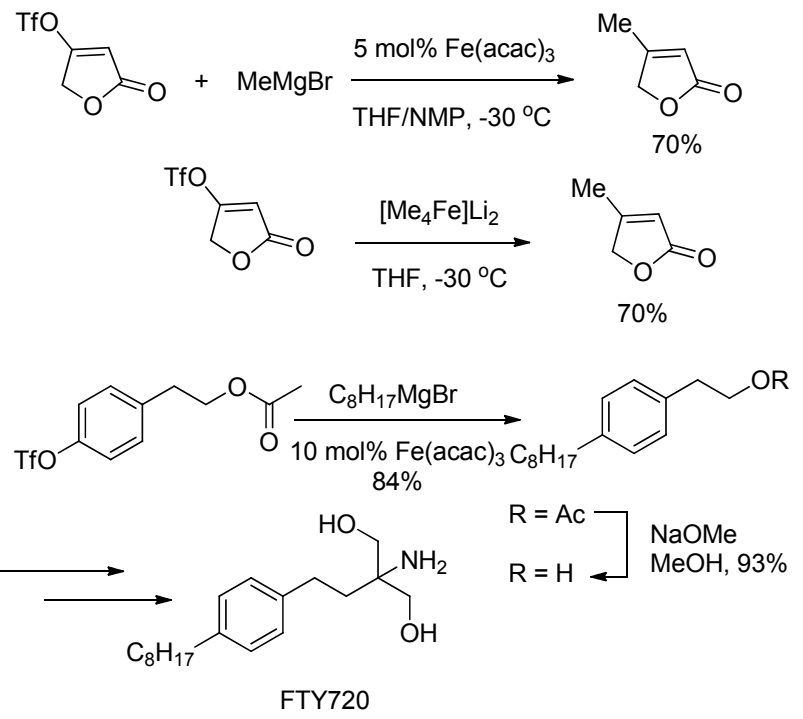

图式 3 铁催化三氟甲磺酸酯的 $\mathrm{C}\left(\mathrm{sp}^{2}\right)-\mathrm{C}\left(\mathrm{sp}^{3}\right)$ 偶联反应 Scheme 3 Iron catalyzed $\mathrm{C}\left(\mathrm{sp}^{2}\right)-\mathrm{C}\left(\mathrm{sp}^{3}\right)$ cross-coupling reaction of triflate
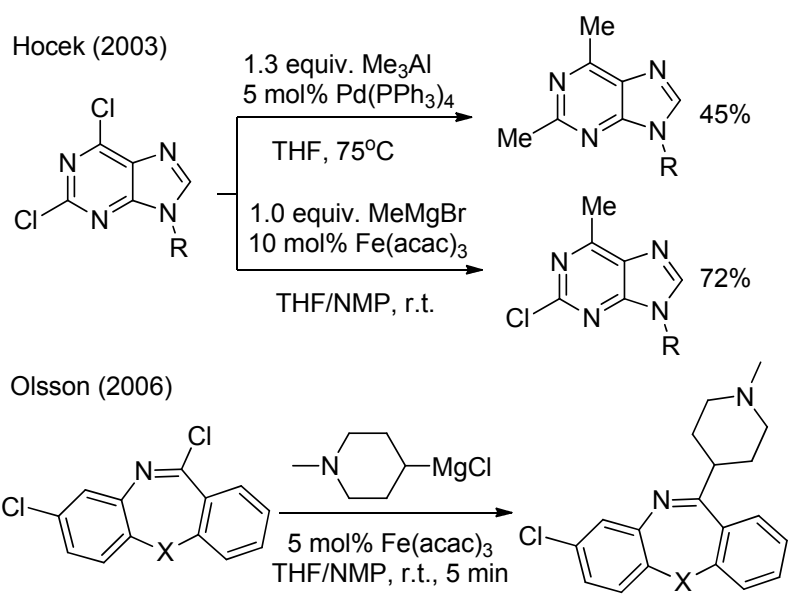

$$
\begin{aligned}
& X=N H, 82 \% \\
& X=O, \quad 71 \% \\
& X=S, \quad 86 \%
\end{aligned}
$$

图式 4 铁催化氯代嘌呤和氯代亚胺的偶联反应

Scheme 4 Iron catalyzed cross-coupling of chloropurines and imidoyl chlorides

并不完全适用于脂肪族卤代烃与芳基格氏试剂的偶联 反应. 在 2004 年, Nakamura 等 ${ }^{[21]}$ 使用 $\mathrm{FeCl}_{3}$ 为催化剂, 在反应中添加了 1.2 equiv. 的 TMEDA, 顺利地实现了二 级卤代烃与芳基格氏试剂的偶联(Scheme 5). 在 Cahiez 的反应体系 $\left[\mathrm{Fe}(\mathrm{acac})_{3} / \mathrm{THF} / \mathrm{NMP}\right]$ 中，只有氯代芳烃的反 应良好，而溴代和碘代芳烃则被还原;而在 Nakamura 的 反应体系中，氯代、溴代和碘代脂肪烃的反应收率都很 好. 美中不足的是, 该反应体系对实验操作要求较高, 格氏试剂和 TMEDA 的混合物需要用注射洜控制加入的 速度，这在一定程度上限制了反应在工业上的应用.

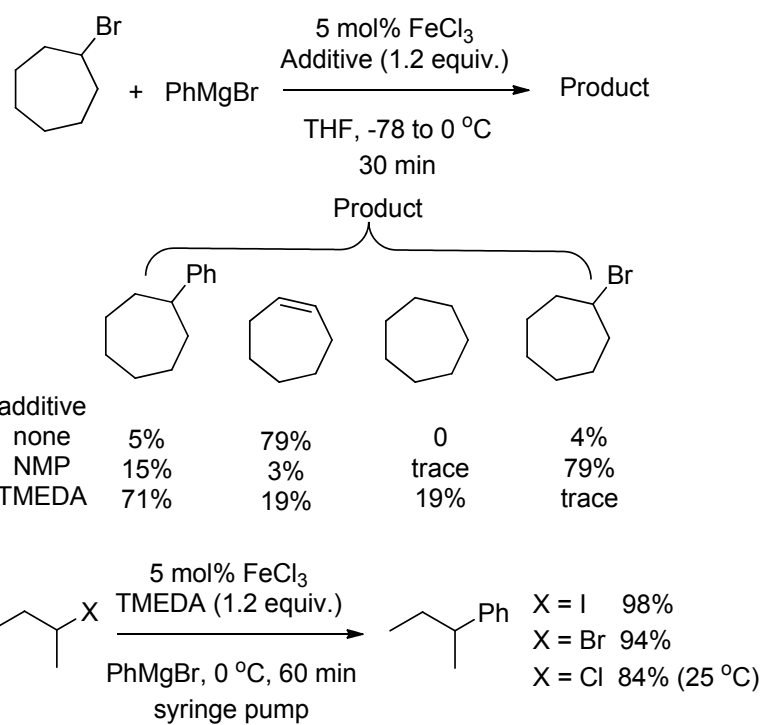

图式 5 铁催化卤代烷烃的 $\mathrm{C}\left(\mathrm{sp}^{2}\right)-\mathrm{C}\left(\mathrm{sp}^{3}\right)$ 偶联反应 Scheme 5 Iron catalyzed $\mathrm{C}\left(\mathrm{sp}^{2}\right)-\mathrm{C}\left(\mathrm{sp}^{3}\right)$ cross-coupling reaction of alkyl halides 
随后, Fürstner 等 ${ }^{[22]}$ 采用络合物 $\mathbf{1}$, 也顺利实现了卤 代烷烃与芳基格氏试剂的偶联反应(Scheme 6). 络合物 1 中 $\mathrm{Fe}(\mathrm{II})$ 与乙烯基的配合较弱, 与 $\mathrm{Li}$ 之间的离子对作 用较强, 类似于 “无机格氏试剂” $\left[\mathrm{Fe}(\mathrm{MgX})_{2}\right]$.

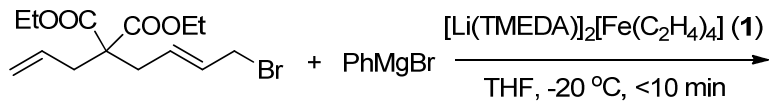

$$
\begin{aligned}
& \overbrace{93 \%}^{\text {COOH }}
\end{aligned}
$$$$
\underset{\mathrm{OEt}}{\mathrm{Br}}+\underset{\mathrm{PhMgBr}}{\stackrel{[\mathrm{Li}(\mathrm{TMEDA})]_{2}\left[\mathrm{Fe}\left(\mathrm{C}_{2} \mathrm{H}_{4}\right)_{4}\right](1)}{\mathrm{THF},-20^{\circ} \mathrm{C},<10 \mathrm{~min}}} \stackrel{\mathrm{Ph}}{\mathrm{O}}
$$$$
87 \%
$$

图式 $6[\mathrm{Li}(\mathrm{TMEDA})]_{2}\left[\mathrm{Fe}\left(\mathrm{C}_{2} \mathrm{H}_{4}\right)_{4}\right]$ 催化的 $\mathrm{C}\left(\mathrm{sp}^{2}\right)-\mathrm{C}\left(\mathrm{sp}^{3}\right)$ 偶联 反应

Scheme $6[\mathrm{Li}(\mathrm{TMEDA})]_{2}\left[\mathrm{Fe}\left(\mathrm{C}_{2} \mathrm{H}_{4}\right)_{4}\right]$ catalyzed $\mathrm{C}\left(\mathrm{sp}^{2}\right)-\mathrm{C}\left(\mathrm{sp}^{3}\right)$ cross-coupling reaction

作为另外一种重要的铁化合物, $\mathrm{Fe}(\mathrm{acac})_{3}$ 在催化脂 肪族卤代烃和芳基格氏试剂的偶联中同样应用广泛. 在 2007 年, Cahiez 等 ${ }^{[23]}$ 使用 $\mathrm{Fe}(\mathrm{acac})_{3}$ 为催化剂, 将 TMEDA 的用量降低至 0.5 equiv., 在催化二级溴代烷烃 和芳基格氏试剂偶联时同样取得了很好的收率(Scheme 7). 他们进一步将 TMEDA 和 HMTA 混合使用, 大大减 少了添加物的用量, 并且取得了良好的效果. 为了克服 $\mathrm{FeCl}_{3}$ 的易吸水性对反应的影响, 作者制备出络合物 $\mathbf{2}$, 这一络合物在室温下可以长期保存且不会吸水, 这对于 铁催化在工业上的应用具有很好的促进作用 (Scheme 7).

随后, Cahiez 等 ${ }^{[24]}$ 使用 $\mathrm{Fe}(\mathrm{acac})_{3}$, TMEDA/HMTA 的 催化体系, 首次实现了铁催化下的乙烯型格氏试剂和脂 肪族溴代烃的偶联反应. 该反应对一级和二级溴代烷烃 均适用, 具有高度的立体选择性(Scheme 8).

Gurinot 等 ${ }^{[25]}$ 也对乙烯型格氏试剂和脂肪族卤代烃 的偶联进行了较为深入的探索. 研究表明, 对于该类偶 联反应, 采用 $\mathrm{Fe}(\mathrm{acac})_{3} / \mathrm{THF} / \mathrm{NMP}$ 体系, $0{ }^{\circ} \mathrm{C}$ 至室温下, 没有产物生成; 而采用 $\mathrm{FeCl}_{3} / \mathrm{TMEDA}$ 体系, $0{ }^{\circ} \mathrm{C}$ 至室温 下, 产物收率最高可达 $98 \%$ (Eq. 2). 在反应过程中, 缓 慢加入乙烯型格氏试剂能提高收率. 另外, 他们通过对 一些反应实例推测, 反应可能是通过自由基历程进行 的.

随后, 他们 ${ }^{[26]}$ 采用这一反应条件完成了 Spirangien A 的核心片段的合成(Scheme 9), 铁催化偶联反应 在由化合物 3 生成 $\mathbf{4}$ 的关键合成步骤中起着难以替代的 作用.
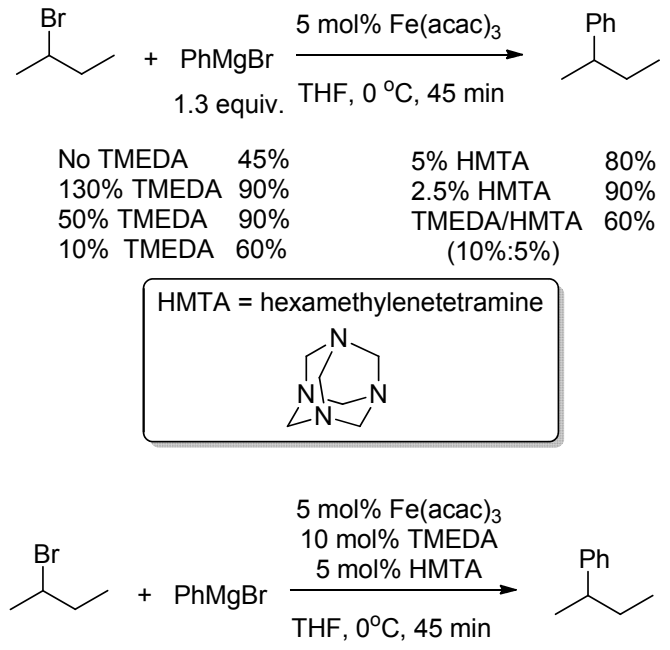

$0.25 \mathrm{~mol}$ scale $88 \%$

$1.5 \mathrm{~mol} \%$

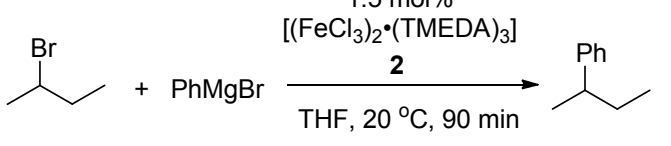

$0.10 \mathrm{~mol}$ scale $78 \%$

图式 7 铁盐/TMEDA-HMTA 体系催化 $\mathrm{C}\left(\mathrm{sp}^{2}\right)-\mathrm{C}\left(\mathrm{sp}^{3}\right)$ 偶联反 应

Scheme 7 Iron salts/HMTA-TMEDA catalyzed $\mathrm{C}\left(\mathrm{sp}^{2}\right)-\mathrm{C}\left(\mathrm{sp}^{3}\right)$ cross-coupling reactions

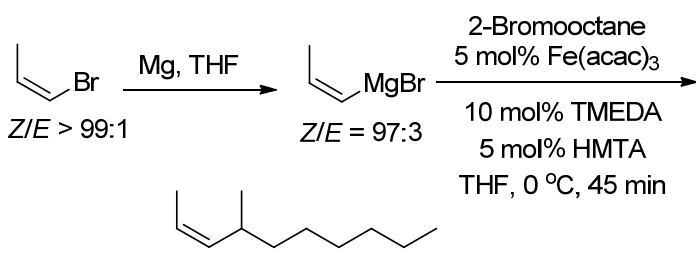

$69 \% Z / E=97: 3$

图式 8 铁盐/TMEDA-HMTA 体系的立体选择性

Scheme 8 Stereoselectivity of iron salts/HMTA-TMEDA
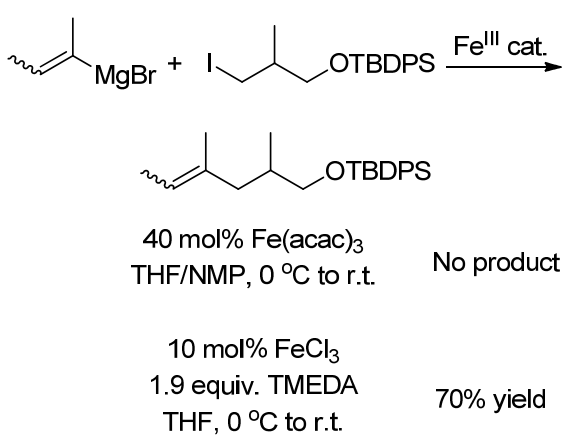

1.1.3 铁催化 $\mathrm{C}\left(\mathrm{sp}^{2}\right)-\mathrm{C}\left(\mathrm{sp}^{3}\right)$ 偶联反应的配体与底物

除了 TMEDA 之外，人们还发展了其它一些含 $\mathrm{N}$ 的 配体(Scheme 10). 如 Bedford 等 ${ }^{[27]}$ 采用的 salen Fe 络合 物和铁-胺催化体系, Chowdhury 等 ${ }^{[28]}$ 采用的铁-胺-双 苯酚型络合物 5 , Yamaguchi 等 ${ }^{[29]}$ 采用的铁- $\beta$-氨基酮络 合物 6 都能有效地催化 $\mathrm{C}\left(\mathrm{sp}^{2}\right)-\mathrm{C}\left(\mathrm{sp}^{3}\right)$ 偶联. 


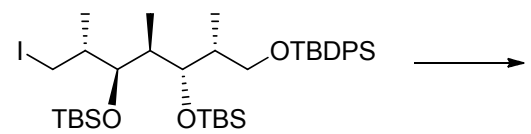

3
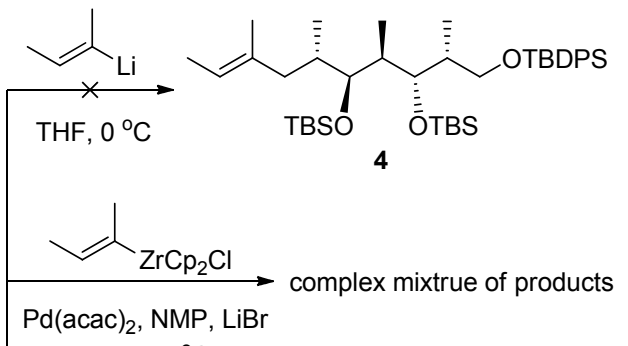

$\mathrm{THF}, 55^{\circ} \mathrm{C}$

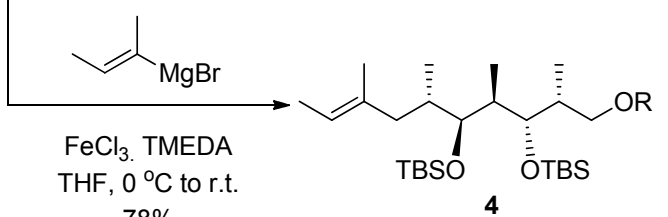
$78 \%$
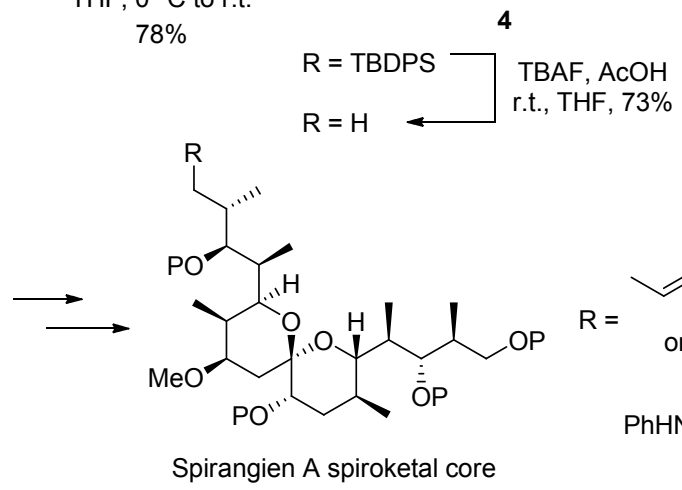<smiles>[R]=[W]</smiles>

图式 9 Spirangien A 核心片段的合成

Scheme 9 Synthesis of spirangien A spiroketal core

膦配体和卡宾配体也能催化 $\mathrm{C}\left(\mathrm{sp}^{2}\right)-\mathrm{C}\left(\mathrm{sp}^{3}\right)$ 偶联的 进行. Bedford 等 ${ }^{[30]}$ 对不同的膦配体和卡宾配体进行了 系统地研究(表 1). 研究发现由 $\mathrm{FeCl}_{3}$ 和膦配体或卡宾配 体原位形成的催化剂均能顺利地实现芳基格氏试剂和 含 $\beta-\mathrm{H}$ 的溴代烷烃的偶联. 对于单膦配体, 三烷基膦优 于三芳基膦; 对于双膦配体, 催化效果随着碳链数的增 加逐渐上升. 对于卡宾配体的催化效果, 1,3-二环已基 氯化咪唑啉(7)、1,3-二叔丁基氯化咪唑啉 (8) 要优于 1,3二异丙叉丙酮基氯化咪唑啉(9)、1,3-二异丙叉丙酮基-2五氟苯基咪唑啉 (10), 鳌合型的卡宾-铁盐加合物 11 同 样能取得优良的催化效果.

与烷基取代的双膦配体相比, 芳基取代的双膦配体 在铁催化芳基锌试剂与脂肪族卤代烃的偶联方面表现 优异. 2009 年 Bedford 课题组 ${ }^{[31]}$ 报道了铁-双膦配合物催 化下溴苄与芳基锌试剂的偶联反应, 其中配合物 12 和 13 的催化效果明显优于 14 (Scheme 11). 同一时期, Nakamura 课题组 ${ }^{[32]}$ 也报道了铁催化下溴代烷烃和多氟 代芳烃锌试剂的偶联反应(Scheme 11). 该反应采用
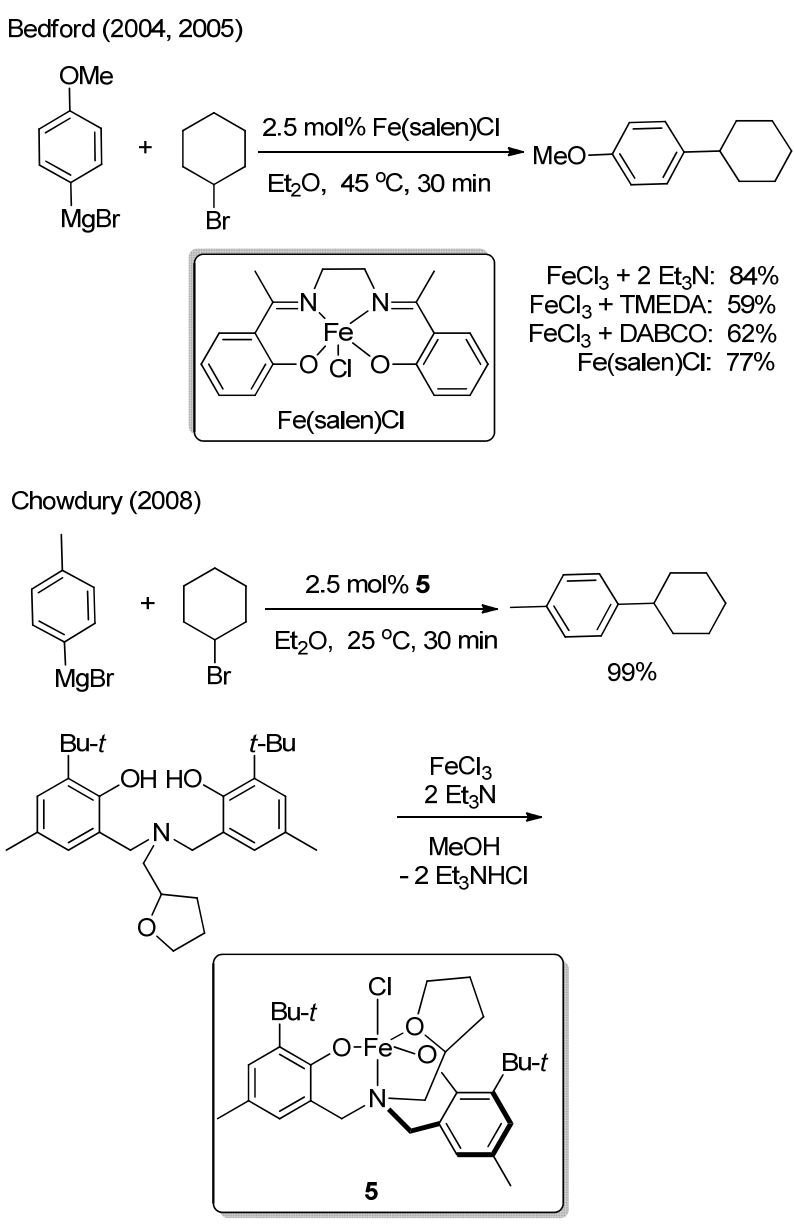

Yamaguchi (2011)

$$
\Upsilon_{6} \mathrm{Br}+\mathrm{PhMgBr} \underset{\mathrm{Et}_{2} \mathrm{O}, \text { r.t., } 5 \mathrm{~min}}{\stackrel{1.0 \mathrm{~mol} \% 6}{\longrightarrow}} \Upsilon_{67 \%}
$$

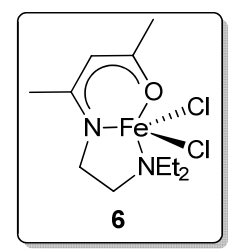

图式 10 铁催化偶联反应中的几种含 $\mathrm{N}$ 配体 Scheme 10 N-ligands for iron catalyzed coupling reactions

$\mathrm{dppBz}$ 为配体或直接使用 $\mathrm{FeCl}_{2}(\mathrm{dppBz})_{2}$ 为催化剂都能 取得很好的收率, 采用 TMEDA 作为配体则没有产物生 成.

长期以来，人们认为活性铁中间体所处的价态从 $\mathrm{Fe}(\mathrm{II})$ 到 $\mathrm{Fe}(0)$ 都有可能, 其中 $\mathrm{Fe}(\mathrm{I})$ 的中间体 Kochi 等 ${ }^{[8 a, 33]}$ 早在 20 世纪 70 年代即认为有可能存在, 但一直未 能得以证实. Bedford 课题组 ${ }^{[34]}$ 在深入研究 $\mathrm{FeCl}_{2}$ $(\mathrm{dppBz})_{2}$ 催化的 Negishi 反应后, 分离出具有催化活性的 $\mathrm{FeX}(\mathrm{dppBz})_{2}$ 中间体. 从而证实在该反应中, $\mathrm{Fe}$ 在动力学 意义上的最低氧化态为 $\mathrm{I}$ 价. 相对于 1,2 -双 (二苯基膦基) 苯 $(\mathrm{dppBz})$, 一般人们认为 1,2 -双 (二苯基膦基)乙烷 
表 1 膦配体和卡宾配体对 $\mathrm{C}\left(\mathrm{sp}^{2}\right)-\mathrm{C}\left(\mathrm{sp}^{3}\right)$ 交叉偶联的影响

Table 1 Influence of phosphine ligands and NHC ligands on the $\mathrm{C}\left(\mathrm{sp}^{2}\right)-\mathrm{C}\left(\mathrm{sp}^{3}\right)$ cross-coupling

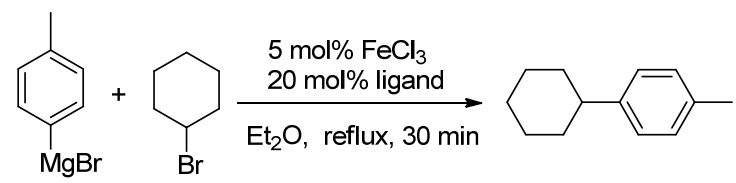

\begin{tabular}{lc||cc}
\hline \multicolumn{1}{c|}{ Ligand } & Yield/\% & Ligand & Yield $\%$ \\
\hline $\mathrm{PPh}_{3}$ & 72 & $\mathrm{Ph}_{2} \mathrm{P}\left(\mathrm{CH}_{2}\right)_{5} \mathrm{PPh}_{2}$ & 87 \\
$\mathrm{P}(\mathrm{OPh})_{3}$ & 67 & $\mathrm{Ph}_{2} \mathrm{P}\left(\mathrm{CH}_{2}\right)_{6} \mathrm{PPh}_{2}$ & 91 \\
$\mathrm{P}(o \text {-tolyl })_{3}$ & 53 & $\mathbf{7}$ & 87 \\
$\mathrm{PCy}$ & 87 & $\mathbf{8}$ & 97 \\
$\mathrm{P}(\mathrm{OMe})_{3}$ & 83 & $\mathbf{9}$ & 45 \\
$\mathrm{Ph}_{2} \mathrm{PCH}_{2} \mathrm{PPh}_{2}$ & 60 & $\mathbf{1 0}$ & 67 \\
$\mathrm{Ph}_{2} \mathrm{P}\left(\mathrm{CH}_{2}\right)_{4} \mathrm{PPh}_{2}$ & 75 & $\mathbf{1 1}$ & 94 \\
\hline
\end{tabular}

Bedford

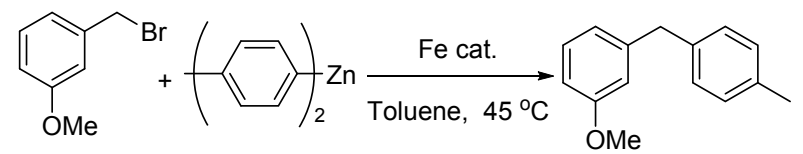

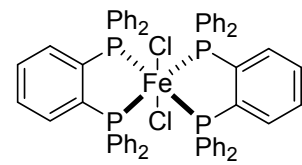

$\mathrm{FeCl}_{2}(\mathrm{dppBz})_{2}$

12

$94 \%$<smiles>Cl[Ge]1(Cl)Pc2ccccc2P1c1ccccc1</smiles>

13

$80 \%$

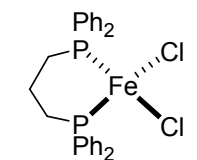

14

$71 \%$

Nakamura
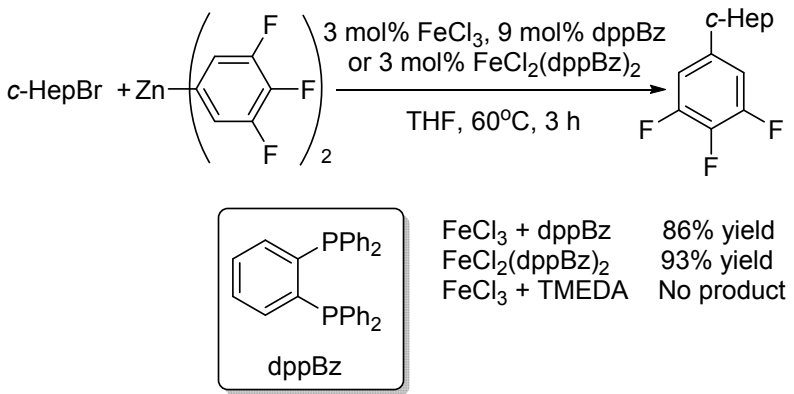

$\mathrm{FeCl}_{3}+\mathrm{dppBz} \quad 86 \%$ yield $\mathrm{FeCl}_{2}(\mathrm{dppBz})_{2} \quad 93 \%$ yield $\mathrm{FeCl}_{3}+$ TMEDA No product

图式 11 铁催化偶联反应中的几种膦配体

Scheme 11 Phosphine ligands for iron catalyzed coupling reactions

(dppe)的活性较差, 2013 年, 该课题组 ${ }^{[35]}$ 采用简单易得 的 dppe 制得 Fe(I)催化剂 15, 用于催化 Negishi 反应反而 获得比 $\mathrm{FeCl}_{2}(\mathrm{dppBz})_{2}$ 更佳的效果(Eq. 3). 由此可见, 在 铁催化的反应中, 催化剂的活性并不是简单地由配体的 电子效应决定的.

相对而言，铁催化的 Suzuki-Miyaura 反应更具挑战 性. 这是因为与格氏试剂、锌试剂等相比, 嶰试剂的亲 核性较低, 有机喼酸或硼酸酯上的亲核基团都没有足够 的活性转移到铁催化剂上 ${ }^{[36]}$, 而转金属化过程在整个

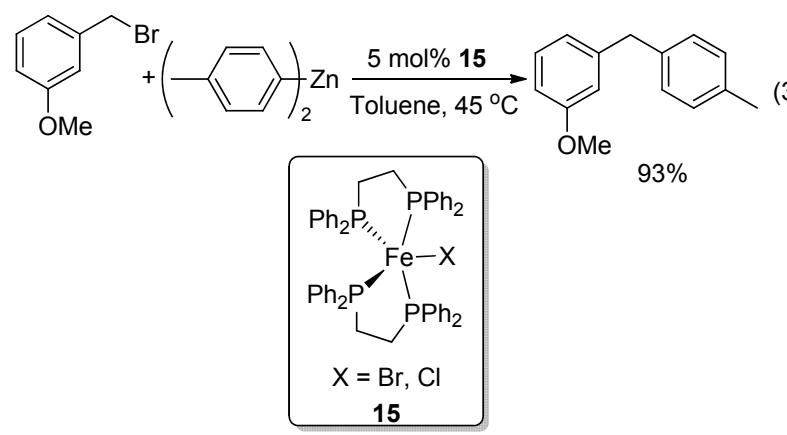

催化循环中起决定作用. 因此，目前除了需要采用活性 较高的铁-双膦催化剂来促进硼一铁之间的转金属过程 外，底物主要局限于亲核性较高的嗍酸盐. 如 2010 2015 年间, Nakamura 课题组 ${ }^{[37]}$ 采用一类新型 铁-双膦 络合物 16、17 相继实现了脂肪族卤代烃与多种类型硼 酸盐的 Suzuki-Miyaura 偶联. 2014 年, Bedford 课题组 ${ }^{[38]}$ 采用类似的 $\mathrm{FeCl}_{2}(\mathrm{dppBz})_{2}$ 也实现了脂肪族卤代烃的 $\mathrm{C}\left(\mathrm{sp}^{3}\right)-\mathrm{C}\left(\mathrm{sp}^{2}\right)$ 型偶联, 并将金属试剂的适用范围由硼 酸盐拓展至 13 族元素如铝、镓、铟等的金属试剂(Scheme 12).

$$
\begin{aligned}
& \text { Nakamura } \\
& \mathrm{R}^{1} \mathrm{X}+\left[\begin{array}{l}
\mathrm{R}^{1}=1^{\circ}, 2^{\circ} \text { Alkyl } \\
\mathrm{R}^{2}=\text { Aryl, Vinyl, Alkynyl, } 1^{\circ} \text { Alkyl etc.; } \\
\mathrm{R}^{3}=i \text {-Pr, } n \text {-Bu, } t \text {-Bu etc.; } \\
\mathrm{M}=\mathrm{Li}, \mathrm{MgCl}, \text { etc. }
\end{array}\right.
\end{aligned}
$$

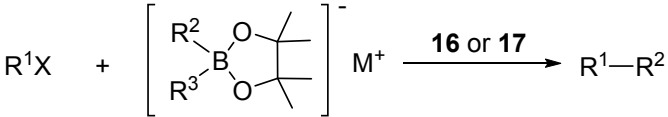

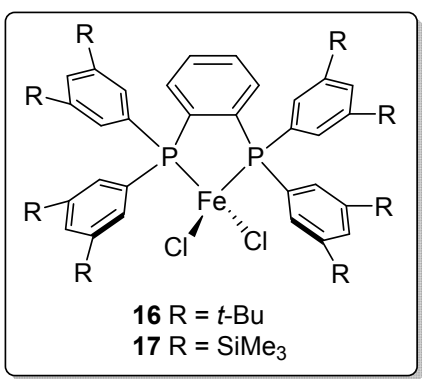

Bedford

$$
\begin{aligned}
& \mathrm{RX}+\underset{\mathrm{Ar} \longrightarrow \mathrm{MR}_{2}}{\stackrel{\left.\mathrm{Ar} \longrightarrow \mathrm{MR}_{3}\right]^{-}}{\stackrel{\mathrm{FeCl}_{2}(\mathrm{dPPBz})_{2}}{\longrightarrow}} \mathrm{R}-\mathrm{Ar}} \mathrm{R}=\text { Alky, Benyl, Allyl } \\
& M=B, A l, G a, I n, T I
\end{aligned}
$$

图式 12 铁催化的 Suzuki 偶联反应

Scheme 12 Iron catalyzed Suzuki coupling reaction

此外，通过手性配体的诱导实现铁催化的不对称反 应是近年来研究热点之一. 尽管早在 2000 年, Nakamura 课题组 ${ }^{[39]}$ 就报道了铁催化烯烃的不对称碳金属化反应. 直到 2015 年, 才由该课题组 ${ }^{[40]}$ 报道了首例铁催化的不 
对称偶联反应. $\alpha$-氯代酯与芳基格氏试剂在 $\mathrm{Fe}(\mathrm{acac})_{3}$ 和 手性双膦配体 18 的催化下, 获得高立体选择性的 $\alpha$-芳 基化产物(Eq. 4).
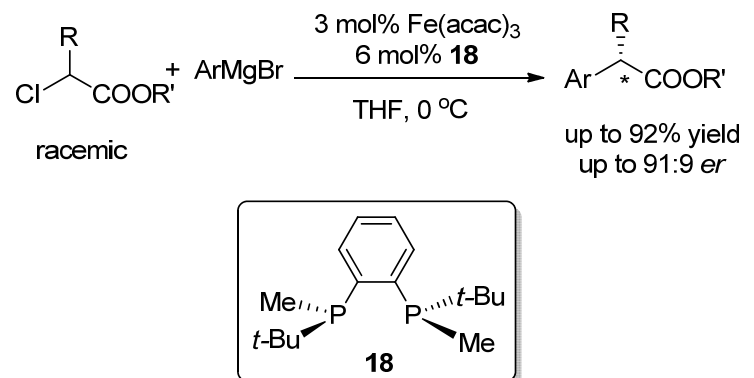

值得一提的是, 近年来还发展出一些不需配体的铁 催化偶联反应. 2011 年, Nakamura 课题组 ${ }^{[41]}$ 采用 $\mathrm{Fe}(\mathrm{acac})_{3}$ 在 $-78{ }^{\circ} \mathrm{C}$ 催化 $\alpha$-溴代羧酸衍生物与芳基格氏 试剂偶联反应, 发现不添加任何配体或添加物时, 收率 甚至优于使用铁-双膦配合物 12 和 16 (Eq. 5). 尽管这一 特殊现象的反应机理仍有待深入研究, 但从该例反应可 以看出, 在催化循环中可能存在多种形式的活性铁物 种, 在某些特定的反应中不依赖于配体也能取得理想的 收率.

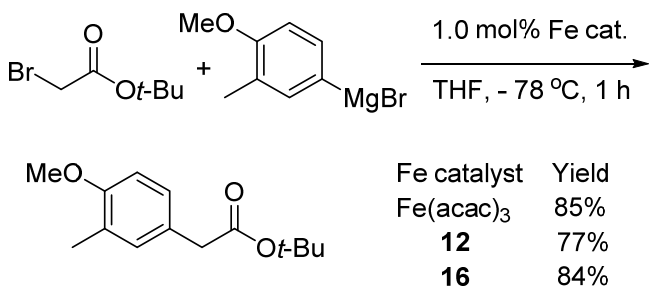

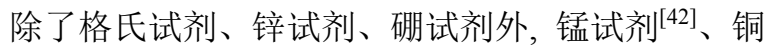
试剂 ${ }^{[43]}$ 等也可以作为亲核试剂在铁催化下发生偶联.

对于亲电试剂, 除了卤代烃、三氟甲磺酸酯外, 其 它一些化合物也可以在铁催化下发生偶联反应. 在 2009 年, Nakamura 课题组 ${ }^{[44]}$ 采用 $\mathrm{FeCl}_{3}$ /TMEDA 催化体 系实现了脂肪族卤代烃及对甲苯磺酸酯与芳基锌试剂 的偶联(Eq. 6). 研究表明: 氯代、溴代、碘代的一级和二 级烷烃均能取得良好的收率, 反应也能耐受多数官能 团. 值得注意的是, 在与对甲苯磺酸酯的偶联中需要添 加镁盐.

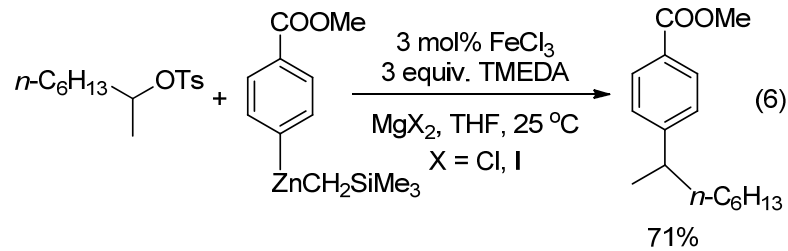

Cahiez 等 ${ }^{[45]}$ 使用 $\mathrm{Fe}(\mathrm{acac})_{3}$ 为催化剂, 实现了共轭末
端双烯磷酸酯与格氏试剂的偶联，这一反应被应用于 Diparopsis castanea 信息素的合成中. Shi 课题组 ${ }^{[46]}$ 采用 异戌酸环己烯酯为底物, 与脂肪族格氏试剂在铁催化下 也顺利地实现了偶联. Agrawal 等 ${ }^{[47]}$ 采用 $N, N$-二甲胺基 磺酸酯为底物, 同样能发生 $\mathrm{C}\left(\mathrm{sp}^{3}\right)-\mathrm{C}\left(\mathrm{sp}^{2}\right)$ 偶联(Scheme 13). 值得注意的是，上述报道中均采用了卡宾配体，对 于避免 $\beta-\mathrm{H}$ 消除和防止产物发生重排十分关键.

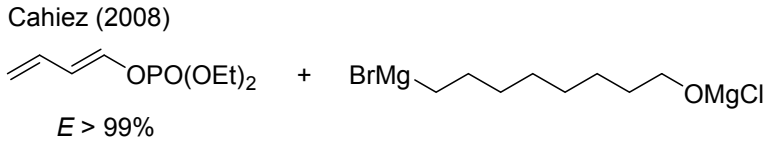

Diparopsis castanea

Shi (2009)

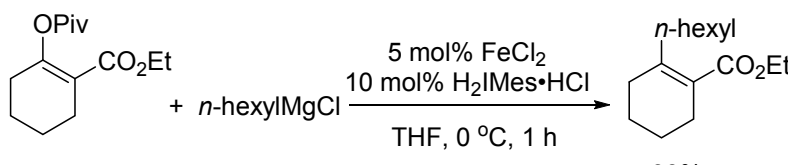

Cook (2013)

$93 \%$

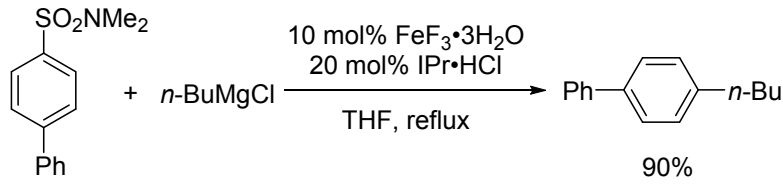

图式 13 铁催化含氧亲电基团的偶联

Scheme 13 Iron catalyzed coupling of electrophilic group containing oxygen atom

对于含 $\mathrm{C}-\mathrm{S}$ 键的亲电试剂的偶联反应同样也有报 道. Itami 等 ${ }^{[48]}$ 采用乙烯基苯基硫醚为亲电试剂, 在铁催 化下与芳基格氏试剂进行偶联，发现反应具有很好的选 择性，产物主要为乙烯基与格氏试剂偶联生成的芳基乙 烯类化合物. Denmark 等 ${ }^{[49]}$ 系统地研究了铁催化下烷基 苯基硫醚、烷基苯基砜等含硫化合物与芳基格氏试剂的 偶联, 发现氧化加成优先发生在 $\mathrm{C}\left(\mathrm{sp}^{3}\right)-\mathrm{S}$ 键上, 进行 $\mathrm{C}\left(\mathrm{sp}^{2}\right)-\mathrm{C}\left(\mathrm{sp}^{3}\right)$ 型偶联. Chandra 等 ${ }^{[50]}$ 采用 $\mathrm{sp}^{3}$ 的磺酰氯为 底物，与芳基格氏试剂在铁催化下反应，顺利地获得了 脱 $\mathrm{SO}_{2}$ 型偶联产物(Scheme 14).

\section{2 铁催化的 $\mathrm{C}\left(\mathrm{sp}^{3}\right)-\mathrm{C}\left(\mathrm{sp}^{3}\right)$ 偶联反应}

迄今为止, 铁催化的 $\mathrm{C}\left(\mathrm{sp}^{3}\right)-\mathrm{C}\left(\mathrm{sp}^{3}\right)$ 偶联反应的报 道很少. 2007 年, Dongol 等 ${ }^{[51]}$ 采用 $\mathrm{Fe}(\mathrm{OAc})_{2}$ 为催化剂, Xantphos 为配体, 在乙醚中完成了一级溴代烷烃与一级 卤代烃格氏试剂的偶联反应，二级溴代烷烃收率很低 (Eq. 7). 


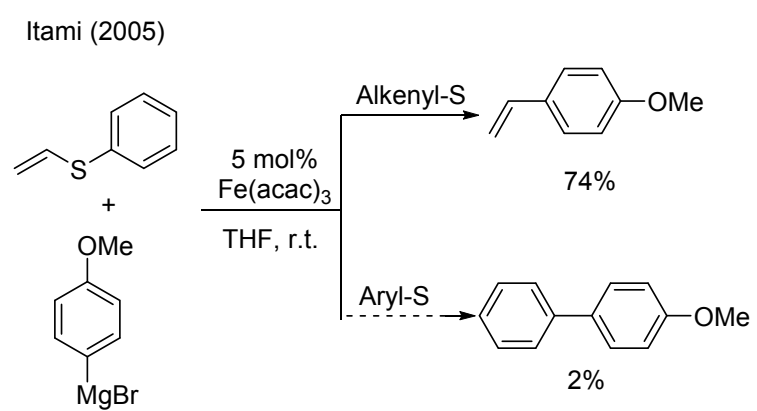

Denmark (2013)
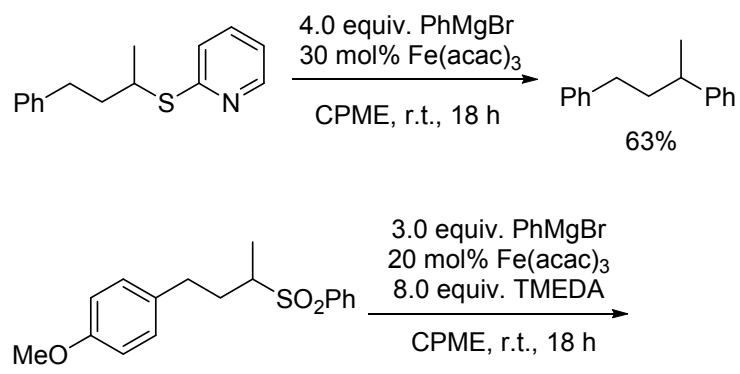<smiles>COc1ccc(CCC(C)c2ccccc2)cc1</smiles>

Chandra (2008)
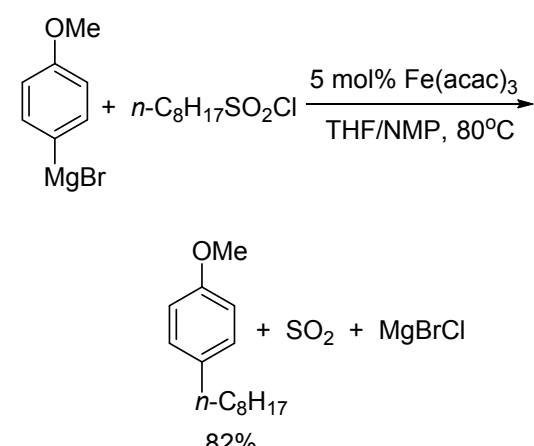

图式 14 铁催化含硫亲电基团的偶联

Scheme 14 Iron catalyzed coupling of electrophilic group containing sulphur atom

$$
n-\mathrm{BuMgBr}+\mathrm{RBr} \underset{\mathrm{Et}_{2} \mathrm{O}, \text { r.t., } 15 \mathrm{~min}}{\stackrel{3 \mathrm{~mol} \% \mathrm{Xantphos}}{\longrightarrow}} n-\mathrm{Bu}-\mathrm{R}
$$

$\mathrm{RBr}=1$-Bromohexadecane $64 \%$ yield $\mathrm{RBr}=$ exo-2-Bromonorbornane $8 \%$ yield

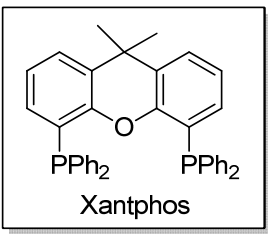

2012 年, Nakamura 课题组 ${ }^{[52]}$ 以 $\mathrm{Fe}(\mathrm{acac})_{3}$ 为催化剂, Xantphos 为配体, 实现了 $\mathrm{C}\left(\mathrm{sp}^{3}\right)-\mathrm{C}\left(\mathrm{sp}^{3}\right)$ 型 Suzuki 偶联 (Scheme 15). 反应所使用的硼试剂可为三烷基硼烷，也 可由末端烯烃与 $\mathrm{BH}_{3} \cdot \mathrm{Me}_{2} \mathrm{~S}$ 混合而成. 成功的关键在于 需要添加 $i-\mathrm{PrMgCl}$ 对三烷基硼烷进行活化以提高其亲 核性, 促进转金属化过程. 一级和二级卤代烃均能顺利 地得到偶联产物.

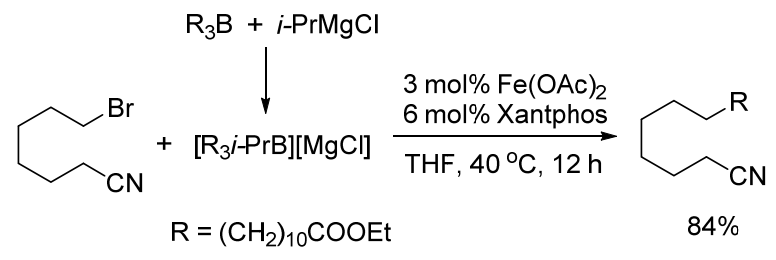

图式 15 铁催化 $\mathrm{C}\left(\mathrm{sp}^{3}\right)-\mathrm{C}\left(\mathrm{sp}^{3}\right)$ 偶联反应

Scheme 15 Iron catalyzed $\mathrm{C}\left(\mathrm{sp}^{3}\right)-\mathrm{C}\left(\mathrm{sp}^{3}\right)$ coupling reaction

1.3 铁催化的 $\mathrm{C}\left(\mathrm{sp}^{2}\right)-\mathrm{C}(\mathrm{sp}) 、 \mathrm{C}\left(\mathrm{sp}^{3}\right)-\mathrm{C}(\mathrm{sp})$ 偶联反应

炔类化合物作为生物活性分子、有机光电材料和有 机中间体在医药、材料、精细化工等领域具有广泛的应 用. 因此，在分子中引入炔基常用的方法即 Sonogashira 反应一直是人们研究的热点之一.

\subsection{1 铁催化的 $\mathrm{C}\left(\mathrm{sp}^{2}\right)-\mathrm{C}(\mathrm{sp})$ 偶联反应}

2008 年, Nakamura 课题组 ${ }^{[53]}$ 报道了首例铁催化的 $\mathrm{C}\left(\mathrm{sp}^{2}\right)$ - $\mathrm{C}(\mathrm{sp})$ 偶联反应. 炔基格氏试剂与卤代烯烃或烯 烃的三氟甲磺酸酯在 $\mathrm{FeCl}_{3}$ 催化下偶联生成共轭烯炔化 合物(Scheme 16). 反应中使用的炔基格氏试剂由末端 炔烃和 $\mathrm{MeMgBr}$ 原位生成, 添加催化量的 HMTA/TMEDA 不能提高收率, 加入化学计量的 TMEDA 后也只获得中等收率, 加入 $\mathrm{LiBr}$ 或 $\mathrm{LiCl}$ 则使收 率得到明显提高. 在此基础上, $\mathrm{Li}$ 等 ${ }^{[54]}$ 直接使用末端炔 烃，在铁催化下与碘代烯烃偶联生成共轭烯炔. 在反应 中使用了 $\mathrm{Cs}_{2} \mathrm{CO}_{3}$ 作为碱, 1,10-邻菲洛啉作配体(Scheme 16).

2008 2009 年，人们相继报道了铁催化碘代芳烃 和烯烃的 Sonogashira 反应(Scheme 17). Bolm 课题组 ${ }^{[55]}$ 采用 $\mathrm{FeCl}_{3}$ 为催化剂, $\mathrm{N}, \mathrm{N}$-二甲基乙烯基二胺(DMEDA) 为配体, $\mathrm{Cs}_{2} \mathrm{CO}_{3}$ 作碱, 高温下长时间反应实现了末端炔 烃和碘代芳烃的偶联. 该反应只对碘代芳烃有效，使用 溴代芳烃或芳烃的三氟甲磺酸酯只有痕量的产物生成. 他们将邻碘苯酚和炔烃偶联后的产物直接在铁催化下 关环生成苯并呋喃衍生物. Mao 等 ${ }^{[6]}$ 采用 $\mathrm{Fe}(\mathrm{acac})_{3}$ 、 $\mathrm{CuI} 、 \mathrm{~K}_{3} \mathrm{PO}_{4}$ 和 $\mathrm{DMSO}$ 的体系也实现了末端炔烃和碘代 芳烃的偶联, 其优势在于该反应不需要配体. Vogel 等 ${ }^{[57]}$ 也报道了类似的反应条件, 其中碱换作 $\mathrm{Cs}_{2} \mathrm{CO}_{3}$, 溶剂为 NMP. 

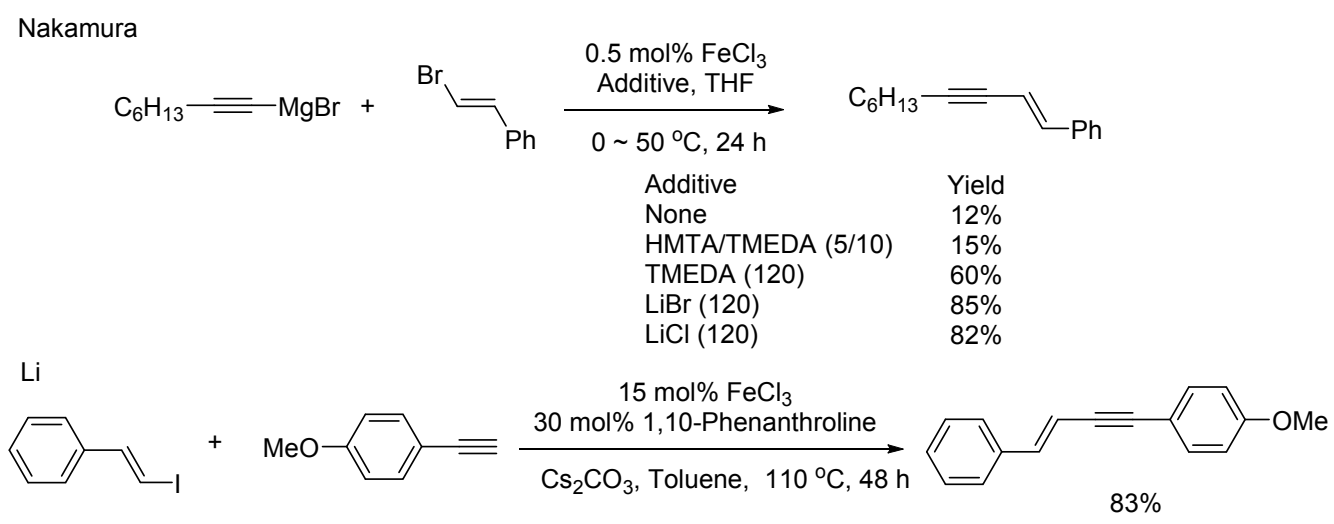

图式 16 铁催化 $\mathrm{C}\left(\mathrm{sp}^{2}\right)-\mathrm{C}(\mathrm{sp})$ 偶联反应

Scheme 16 Iron catalyzed $\mathrm{C}\left(\mathrm{sp}^{2}\right)-\mathrm{C}(\mathrm{sp})$ coupling reaction

Bolm (2008)
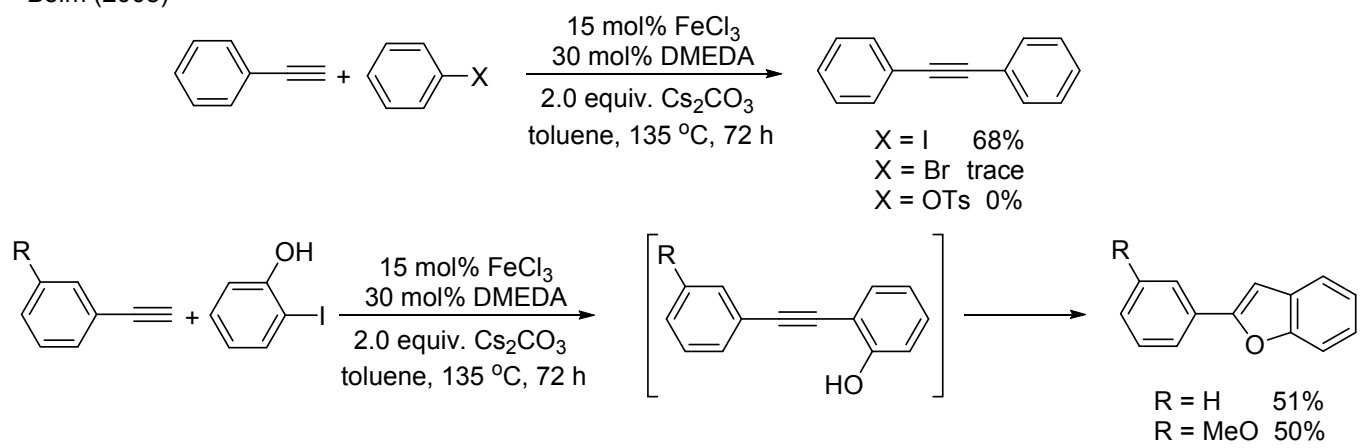

Mao (2008)

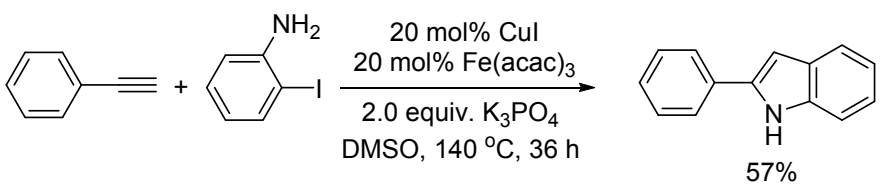

Vogel (2008)

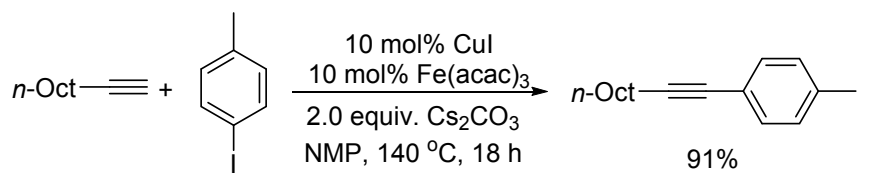

图式 17 铁催化的 sonogashira 反应

Scheme 17 Iron catalyzed sonogashira reaction

\subsection{1 铁催化的 $\mathrm{C}\left(\mathrm{sp}^{3}\right)-\mathrm{C}(\mathrm{sp})$ 偶联反应}

2011 年, Nakamura 课题组 ${ }^{[58]}$ 报道了首例铁催化的 $\mathrm{C}\left(\mathrm{sp}^{3}\right)-\mathrm{C}(\mathrm{sp})$ 型 Sonogashira 反应(Scheme 18). 他们采 用大位阻的双膦配体与铁形成络合物 16. 其中 $\mathrm{Fe}$ 的 氧化态为 II 价并呈电中性, 同时呈高自旋态, 有利于 以自由基形式与 $\mathrm{sp}^{3}$ 杂化的 $\mathrm{C}-\mathrm{X}$ 键发生氧化加成, 从 而实现了不活泼的脂肪族卤代烃与炔基格氏试剂的偶 联反应. 2015 年, 该课题组 ${ }^{[59]}$ 采用该催化剂又完成了 不活泼卤代烃与炔基硼锂试剂的 Suzuki 偶联. 以上工 作为合成含炔基的功能分子提供了一种新方法.

2014 年, Cheung 等 ${ }^{[60]}$ 采用 $\mathrm{FeBr}_{2}$ 催化也实现了不 活泼的二级溴代或碘代烷烃与炔基格氏试剂的偶联反
应(Eq. 8). 与 Nakamura 的方法相比, 该反应室温即可 进行, 且无需添加膦配体, 底物适用范围更广.

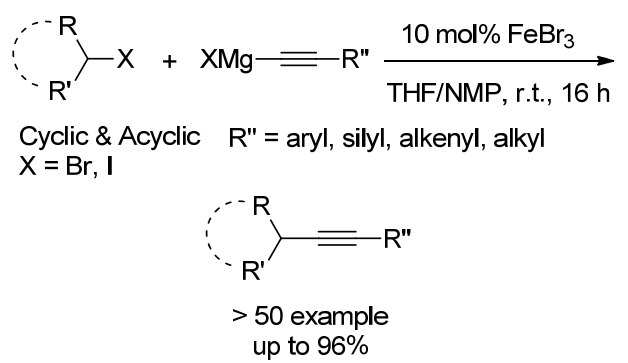

\section{4 催化的 $\mathrm{C}\left(\mathrm{sp}^{2}\right)-\mathrm{C}\left(\mathrm{sp}^{2}\right)$ 偶联反应}

联芳烃类化合物作为药物、配体、液晶材料等分 

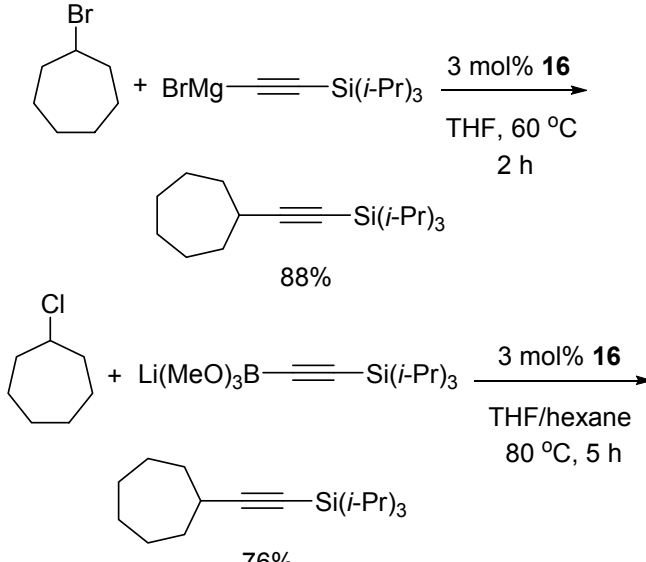

$76 \%$

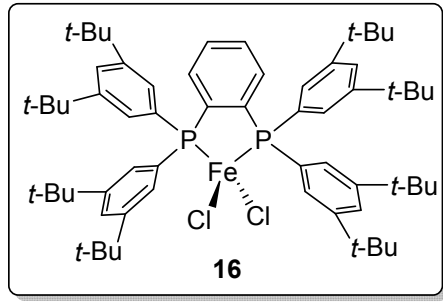

图式 18 铁催化的 $\mathrm{C}\left(\mathrm{sp}^{3}\right)-\mathrm{C}(\mathrm{sp})$ 偶联反应

Scheme 18 Iron catalyzed $\mathrm{C}\left(\mathrm{sp}^{3}\right)-\mathrm{C}(\mathrm{sp})$ coupling reaction

子的重要结构单元, 在药物化学、配位化学及材料化学 等领域有着广泛的应用. 基于铁廉价、无毒等优点, 铁 催化的 $\mathrm{C}\left(\mathrm{sp}^{2}\right)-\mathrm{C}\left(\mathrm{sp}^{2}\right)$ 型偶联反应越来越受人们重视. 但与 $\mathrm{C}\left(\mathrm{sp}^{3}\right)-\mathrm{C}\left(\mathrm{sp}^{2}\right)$ 型偶联反应相比, 文献中铁催化的 $\mathrm{C}\left(\mathrm{sp}^{2}\right)-\mathrm{C}\left(\mathrm{sp}^{2}\right)$ 型偶联反应的研究明显偏少, 其中最大 的挑战在于避免金属试剂的自身偶联.

2002 年, Quintin 等 ${ }^{[61]}$ 采用 $\mathrm{Fe}(\mathrm{acac})_{3}$ 催化溴代和氯 代的吡啶、喹啉与苯基格氏试剂偶联, 取得了中等的收 率. 2005 年, Ludovic 等 ${ }^{[62]}$ 采用 $\mathrm{Fe}(\mathrm{acac})_{3}$ 催化氯代吡嗪与 芳基格氏试剂偶联(Scheme 19).

Quintin (2002)

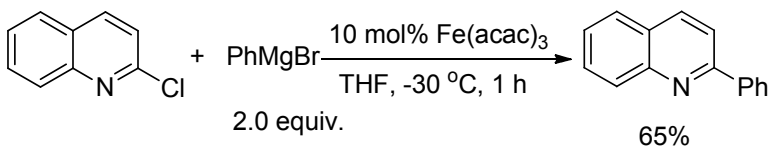

Ludovic (2005)

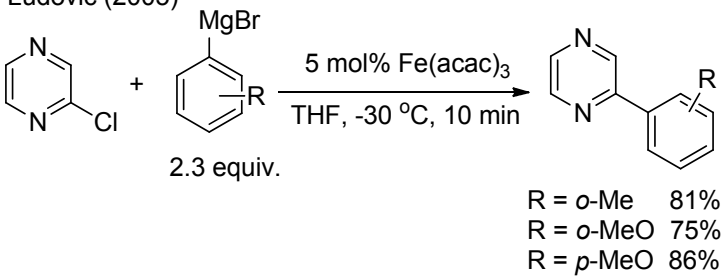

图式 $19 \mathrm{Fe}(\mathrm{acac})_{3}$ 催化的 $\mathrm{C}\left(\mathrm{sp}^{2}\right)-\mathrm{C}\left(\mathrm{sp}^{2}\right)$ 偶联

Scheme $19 \mathrm{Fe}(\mathrm{acac})_{3}$ catalyzed $\mathrm{C}\left(\mathrm{sp}^{2}\right)-\mathrm{C}\left(\mathrm{sp}^{2}\right)$ coupling reaction

这些实例表明: 尽管铁催化的 $\mathrm{C}\left(\mathrm{sp}^{2}\right)-\mathrm{C}\left(\mathrm{sp}^{2}\right)$ 型偶
联反应取得了一些进展，但仍存在以下问题：(1)这些反 应基本上只适用于缺电子卤代氮杂环化合物; (2)反应对 底物的官能团耐受性差, 在这些报道中还没有出现带官 能团的卤代烃; (3)格氏试剂自身偶联的副产物无法抑 制，所以反应所需的格氏试剂往往是大过量的(为卤代 芳烃的数倍).

为了避免格氏试剂的自身偶联对反应的影响，人们 分别对催化体系和金属试剂进行了调整.

2012 年, Knochel 课题组 ${ }^{[63]}$ 报道了 $\mathrm{FeBr}_{3}$ 催化的 $N$ 杂环卤代烃和芳基格氏试剂的偶联反应(Scheme 20). 与 Quintin 和 Ludovic 的方法相比，该方法具有底物适用 范围更广、收率更高的优点，而其成功的关键在于反应 中采用了 $\mathrm{THF} / t-\mathrm{BuOMe}$ 混合溶剂. 值得注意的是, 喹啉 类底物的反应速率要大大快于其它 $N$-杂环类底物, 由 此他们推测喹啉可以起到加速反应的作用. 2013 年, 该 课题组 ${ }^{[64]}$ 在此基础上添加催化量的喹啉或异喹啉作为 配体，使反应时间由 $2 \mathrm{~h}$ 缩短至 $5 \mathrm{~min}$, 并且收率进一步 增加.

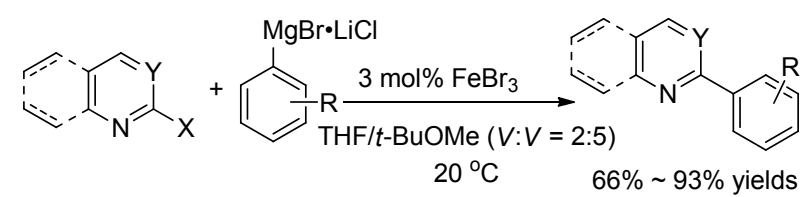

$\mathrm{Z}=\mathrm{H}, \mathrm{N}$, etc.

$\mathrm{R}=\mathrm{H}, 4-\mathrm{Me}, 3-\mathrm{CF}_{3}, 4-\mathrm{F}, 3,5-(\mathrm{MeO})_{2}$, 4-OPiv, 3-OBoc, etc.

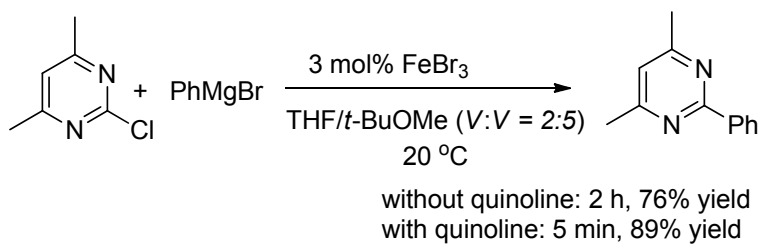

图式 $20 \mathrm{FeBr}_{3}$ 催化的 $\mathrm{C}\left(\mathrm{sp}^{2}\right)-\mathrm{C}\left(\mathrm{sp}^{2}\right)$ 偶联

Scheme $20 \mathrm{FeBr}_{3}$ catalyzed $\mathrm{C}\left(\mathrm{sp}^{2}\right)-\mathrm{C}\left(\mathrm{sp}^{2}\right)$ coupling reaction

Nakamura 课题组 ${ }^{[65]}$ 采用 $\mathrm{FeF}_{3} \cdot 3 \mathrm{H}_{2} \mathrm{O}$ 与卡宾的催化 体系，有效地抑制了格氏试剂的自身偶联. 在此基础上, 该课题组又发展出 $\mathrm{CoF}_{2} 、 \mathrm{NiF}_{2}$ 等催化剂(表 2) ${ }^{[66]}$, 同样 能高选择性地得到交叉偶联产物. 从这些反应结果不难 看出，该催化体系的确有效地抑制了自身偶联副反应。 但反应条件剧烈，从而使反应无法耐受对格氏试剂敏感 的官能团，且反应只适用于氯代物. 2014 年, Agrawal 等 ${ }^{[67]}$ 使用 $N, N$-二甲胺基磺酸酯和对甲苯磺酸酯为亲电 试剂, 在 $\mathrm{FeF}_{3} \cdot 3 \mathrm{H}_{2} \mathrm{O}-\mathrm{IPr} \bullet \mathrm{HCl}$ 催化体系中也顺利地实现 了 $\mathrm{C}\left(\mathrm{sp}^{2}\right)-\mathrm{C}\left(\mathrm{sp}^{2}\right)$ 偶联(Eq. 9).

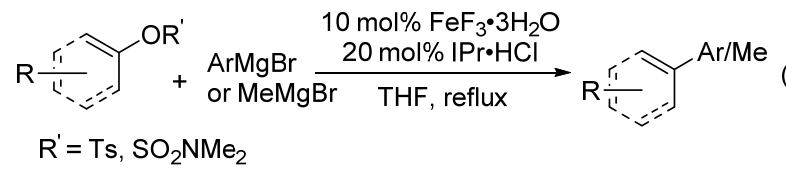


表 2 催化剂和添加剂种类对 $\mathrm{C}\left(\mathrm{sp}^{2}\right)-\mathrm{C}\left(\mathrm{sp}^{2}\right)$ 交叉偶联的影响

Table 2 Influence of catalysts and additives on $\mathrm{C}\left(\mathrm{sp}^{2}\right)-\mathrm{C}\left(\mathrm{sp}^{2}\right)$ cross-coupling

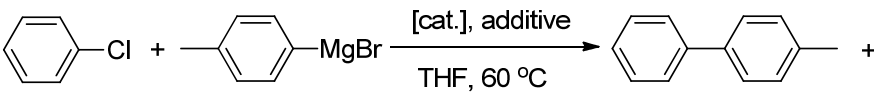

18

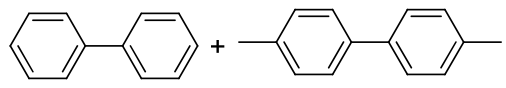

19
20

\begin{tabular}{|c|c|c|c|c|c|c|}
\hline Entry & Catalyst (mol\%) & Additive (mol\%) & Time/h & $18 / \%$ & $19 / \%$ & $20 / \%$ \\
\hline 1 & $\mathrm{FeCl}_{3}(5)$ & $\mathrm{SIPr} \bullet \mathrm{HCl}(15)$ & 24 & 32 & 2 & 32 \\
\hline 2 & $\mathrm{Fe}(\mathrm{acac})_{3}(5)$ & $\mathrm{SIPr} \bullet \mathrm{HCl}(15)$ & 24 & 26 & 2 & 29 \\
\hline 3 & $\mathrm{FeF}_{3} \cdot 3 \mathrm{H}_{2} \mathrm{O}(5)$ & SIPr•HCl (15) & 24 & 98 & Trace & 4 \\
\hline 4 & $\mathrm{FeF}_{3}(5)$ & $\mathrm{SIPr} \bullet \mathrm{HCl}(15)$ & 24 & 29 & Trace & 2 \\
\hline 5 & $\mathrm{CoCl}_{2} \cdot 6 \mathrm{H}_{2} \mathrm{O}(3)$ & $\mathrm{IPr} \bullet \mathrm{HCl}(6)$ & 48 & 68 & 11 & 15 \\
\hline 6 & $\mathrm{CoF}_{2} \bullet 4 \mathrm{H}_{2} \mathrm{O}(3)$ & IPr•HCl (6) & 48 & 95 & 3 & 11 \\
\hline 7 & $\mathrm{NiCl}_{2} \cdot 6 \mathrm{H}_{2} \mathrm{O}(1)$ & $\mathrm{IPr} \bullet \mathrm{HCl}(2)$ & 15 & 60 & 18 & 22 \\
\hline 8 & $\mathrm{NiF}_{2}(\mathbf{1})$ & IPr•HCl (2) & 24 & 95 & 3 & 11 \\
\hline 9 & $\mathrm{NiF}_{2}(1)$ & $\mathrm{PPh}_{3}(4)$ & 16 & 93 & 6 & 14 \\
\hline
\end{tabular}<smiles>CCc1ncn(-c2c(C(C)C)cccc2C(C)C)[n+]1-c1cccc(C(C)C)c1</smiles>

$\mathrm{SIPr} \cdot \mathrm{HCl}$

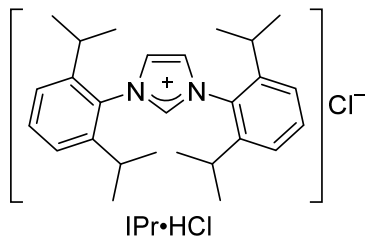

在同一时期, Knochel 课题组 ${ }^{[43]}$ 采用铜试剂(格氏试 剂中加入 $\mathrm{CuCN} \cdot 2 \mathrm{LiCl}$, 原位生成铜试剂)以降低金属试 剂的活性，从而在一定程度上抑制了自身偶联，且使反 应的官能团耐受性也得到了改善(Scheme 21).

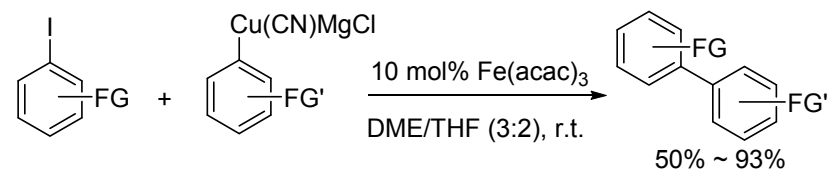
$\mathrm{FG}=$ COOEt, OMe, OTf; FG' $=$ COOEt, COPh, COMe, CN, CONR 2

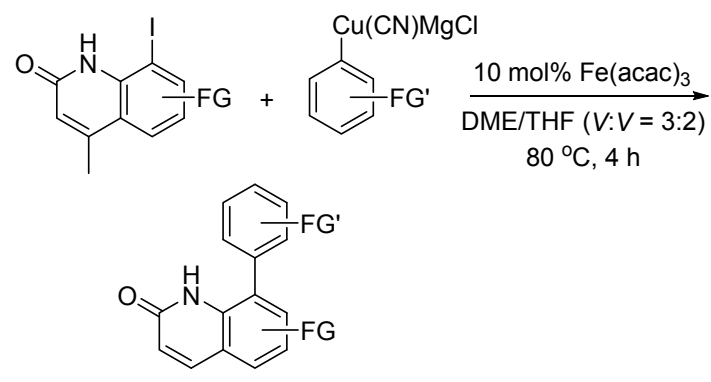

up to $96 \%$

图式 21 铁催化铜试剂的 $\mathrm{C}\left(\mathrm{sp}^{2}\right)-\mathrm{C}\left(\mathrm{sp}^{2}\right)$ 偶联反应 Scheme 21 Iron catalyzed $\mathrm{C}\left(\mathrm{sp}^{2}\right)-\mathrm{C}\left(\mathrm{sp}^{2}\right)$ coupling of organocopper reagents

采用该方法，可以对未保护的喹诺酮实行芳基化. 实验表明, 在 $\mathrm{Fe}(\mathrm{acac})_{3}$ 催化下, 碘代芳烃与芳基铜试剂 的偶联取得了较高的收率; 当卤代芳烃的邻位为酮羰基 时, 溴代和氯代芳烃的偶联收率也不错. 这也再次表明,
铁催化的此类反应对卤代烃的活性高度敏感.

从上面的实例中可以看出, 铁催化的这些反应, 要 么对卤代物有很高的要求(卤素邻位有活化基团 $\mathrm{C}=\mathrm{N}$, $\mathrm{C}=\mathrm{O}$ 或 $\mathrm{C}=\mathrm{C}$ ); 要么对催化体系和反应条件有很高的 要求. 因此建立适用范围广、条件温和、选择性高的 $\mathrm{C}\left(\mathrm{sp}^{2}\right)-\mathrm{C}\left(\mathrm{sp}^{2}\right)$ 偶联反应, 仍将是铁催化重要的研究方 向之一.

\section{2 铁催化的氧化偶联和还原偶联反应}

\section{1 铁催化的氧化偶联反应}

除了过渡金属催化的金属试剂与卤代烃的偶联反 应之外，过渡金属催化的金属试剂间的氧化偶联反应也 是构建碳一碳键的一个重要方法, 这方面已有综述进行 了总结 ${ }^{[68]}$. 与前者相比该方法具有独特的优势：一方 面，可以避免因不活泼卤代烃难以进行氧化加成导致反 应需要添加特殊的配体 ${ }^{[69]}$; 另一方面, 随着芳杂环直接 金属化反应的蓬勃发展，可选用的金属试剂种类丰富， 特别是含官能团的芳杂环金属试剂极大地拓展了反应 的适用范围 ${ }^{[70]}$. 迄今为止, 铁催化下金属试剂的氧化偶 联反应，绝大多数只局限于自身氧化偶联，显然对交叉 偶联而言，自身偶联副反应仍是最大的挑战。

2005 年, Nagano 等 ${ }^{[71]}$ 报道了 $\mathrm{FeCl}_{3}$ 催化的芳基格氏 试剂自身氧化偶联反应. 反应采用 $\mathrm{ClCH}_{2} \mathrm{CH}_{2} \mathrm{Cl}$ 作氧化 剂, 在室温下进行(Scheme 22). 同年, Cahiez 等 ${ }^{[72]}$ 报道 了类似的反应，用活性较高的 $\mathrm{BrCH}_{2} \mathrm{CH}_{2} \mathrm{Br}$ 或 $\mathrm{ICH}_{2} \mathrm{CH}_{2} \mathrm{I}$ 做氧化剂，反应在低温下进行，能耐受酯基、氧基、硝 基等官能团(Scheme 22).

2007 年, Cahiez 等 ${ }^{[73]}$ 又报道了采用空气作为氧化 剂，铁催化下格氏试剂的自身氧化偶联反应. 该反应同 样能耐受多种官能团, 采用 $\mathrm{MnCl}_{2} \cdot \mathrm{LiCl}$ 为催化剂反应、 
Nagano (2005)

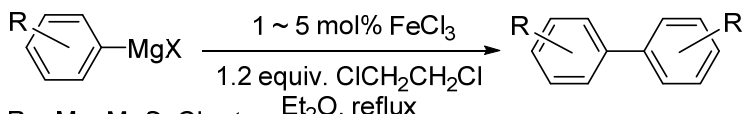

$\mathrm{R}=\mathrm{Me}, \mathrm{MeO}, \mathrm{Cl}$, etc. $\mathrm{Et}_{2} \mathrm{O}$, reflux

$46 \% \sim 100 \%$

Cahiez (2005)

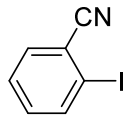

$$
\begin{gathered}
\underset{\text { (1) } i-\mathrm{PrMgBr}, \mathrm{THF},-35^{\circ} \mathrm{C}}{\longrightarrow} \\
\stackrel{\text { (2) } 3 \mathrm{~mol} \% \mathrm{FeCl}_{3}}{1.2 \text { equiv. } \mathrm{ICH}_{2} \mathrm{CH}_{2} \mathrm{I}} \\
\text { THF, }-40^{\circ} \mathrm{C}
\end{gathered}
$$

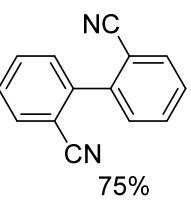

图式 22 铁催化的自身氧化偶联反应

Scheme 22 Iron catalyzed oxidative homo-coupling reactions 也能顺利进行. 随后, Lei 课题组 ${ }^{[74]}$ 采用氧气作为氧化 剂, 实现了铁催化下格氏试剂的自身氧化偶联反应. 作 者在该反应中采用联吡啶作为配体, 使得反应收率大幅 升高. 氧气作为一种清洁友好的氧化剂, 使这类反应变 得更加环境友好. 2010 年, Truong 等 ${ }^{[75]}$ 报道了铁催化下, 在 $t$-BuOLi 作用下杂环芳烃的 $\mathrm{C}-\mathrm{H}$ 活化型氧化偶联反 应(Scheme 23).

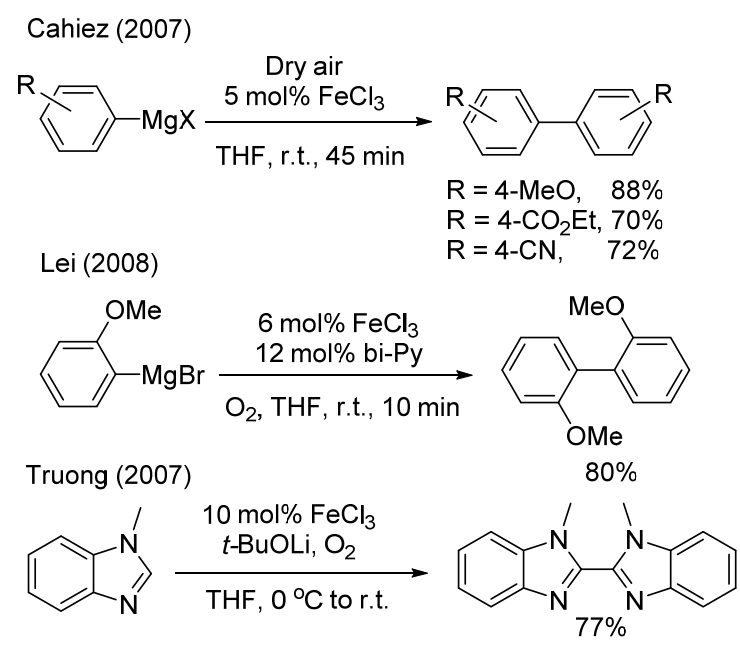

图式 23 以氧气为氧化剂的自身氧化偶联反应

Scheme 23 Homo-coupling reactions which oxygen act as oxidant

长期以来, 铁催化下两种格氏试剂的氧化型交叉偶 联一直是难以突破的瓶颈. 铁催化下锌试剂的氧化偶联 也仅见一例, 即 Caheiz 等 ${ }^{[76]}$ 于 2009 年报道的 $\mathrm{Fe}(\mathrm{acac})_{3}$ 催化的 $\mathrm{C}\left(\mathrm{sp}^{3}\right)-\mathrm{C}\left(\mathrm{sp}^{2}\right)$ 交叉偶联反应(Eq. 10).

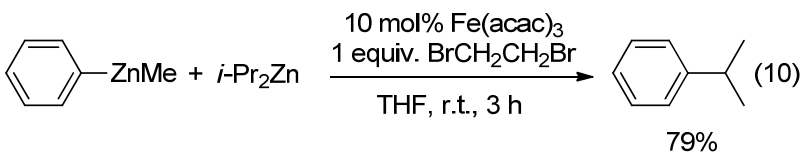

在 2015 年, 我们课题组 ${ }^{[77]}$ 首次建立了铁钛协同型 含氮杂环金属试剂与芳基金属试剂的氧化交叉偶联反 应, 为含氮杂环类联芳烃化合物的合成提供了一种新的
合成方法(Scheme 24).

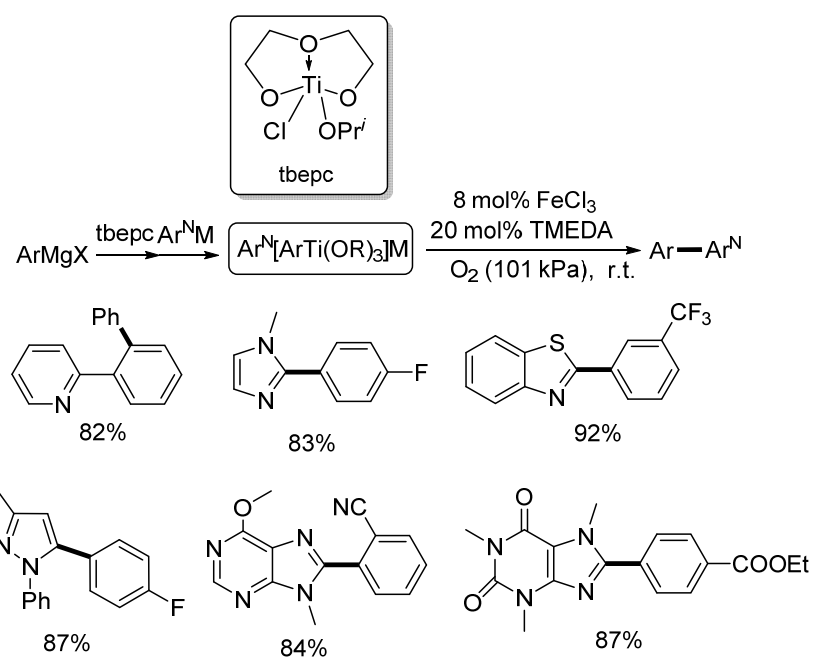

图式 24 铁钛协同型 $\mathrm{Ar}^{\mathrm{N}}-\mathrm{M}$ 与 $\mathrm{Ar}-\mathrm{M}$ 的氧化偶联反应 Scheme 24 Iron/titanate cooperatively oxidative coupling between $\mathrm{Ar}^{\mathrm{N}}-\mathrm{M}$ and $\mathrm{Ar}-\mathrm{M}$

该合成方法只需简单的催化体系 $\left(\mathrm{FeCl}_{3} / \mathrm{TMEDA}\right)$, 以 $\mathrm{O}_{2}$ 作为氧化剂，等物质的量的两种金属试剂在钛试 剂的参与下于室温下以高收率顺利实现交叉偶联. 研究 过程中发现, ate-络合物 $\operatorname{Ar}^{\mathrm{N}}\left[\operatorname{ArTi}(\mathrm{OR})_{3}\right] \mathrm{M}$ 的形成对于抑 制芳基金属试剂自身偶联起着至关重要的作用。该反应 适用于几乎所有的常见含氮杂环，并可耐受酮基、酯基、 酰胺、氰基等基团. 利用该方法, 我们还实现了 carboxamycin 和 $(S)$-nicotine 衍生物的新法合成.

在此基础上, 我们课题组 ${ }^{[78]}$ 进一步研究了结构相 似的芳基格氏试剂间的氧化交叉偶联反应(Scheme 25). 与之前的工作相比，这无疑更具挑战性，因为两种活性 相近的格氏试剂之间的竞争将造成严重的自身偶联副 反应. 在这类偶联中, 我们首次使用了混合型双芳基钛 试剂( $\left.\operatorname{Ar}\left[\mathrm{Ar}^{\prime} \mathrm{Ti}(\mathrm{OR})_{3}\right] \mathrm{M}\right)$. 值得注意的是, 通过改变芳基 金属试剂与 $\operatorname{ClTi}(\mathrm{OR})_{3}$ 的结合顺序而形成的两种钛试剂 $\left(\operatorname{Ar}\left[\operatorname{Ar} ' \mathrm{Ti}(\mathrm{OR})_{3}\right] \mathrm{MgX}\right.$ 和 $\left.\operatorname{Ar}^{\prime}\left[\operatorname{ArTi}(\mathrm{OR})_{3}\right] \mathrm{MgX}\right)$ 在反应活性 上表现出明显差异，这在相关金属 ate-络合物中尚属首 次发现. 正是利用这一活性差异，等物质的量的两种结 构相似的芳基金属试剂可在 $\mathrm{FeCl}_{3} / \mathrm{TMEDA}$ 催化下，以 $\mathrm{O}_{2}$ 为氧化剂, 顺利地进行氧化偶联.

\section{2 铁催化的还原偶联反应}

氧化偶联的底物为两分子亲核试剂. 相对应地，两 分子亲电试剂在还原剂存在下，经金属催化实现偶联是 构建碳一碳键的另一条重要途径.

2006 年, Xu 等 ${ }^{[79]}$ 报道了铁催化溴代烃的自身还原 偶联(Eq. 11). 该反应具有 “一锅法” 的特点，只需在体 系中加入 $\mathrm{Mg}$ 而不必将溴代烃先制成格氏试剂. C( $\left.\mathrm{sp}^{3}\right)-$ 


$$
\begin{aligned}
& \operatorname{ArMgX} \stackrel{\text { tbepc }}{\longrightarrow} \stackrel{\operatorname{Ar} M g X}{\longrightarrow} \operatorname{Ar}\left[\operatorname{ArTi}(\mathrm{OR})_{3}\right] \mathrm{MgX} \quad 8 \mathrm{~mol} \% \mathrm{FeCl}_{3}
\end{aligned}
$$

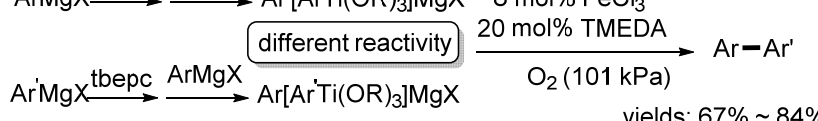

$$
\begin{aligned}
& \mathrm{Ar}=\mathrm{Ph}, 4-\mathrm{MeOC}_{6} \mathrm{H}_{4}, 4-\mathrm{MeC}_{6} \mathrm{H}_{4}, 2-\mathrm{MeC}_{6} \mathrm{H}_{4}, 4-\mathrm{FC}_{6} \mathrm{H}_{4} \\
& \text { 4-EtOOCC } 6 \mathrm{H}_{4}, 1-\mathrm{Naphthyl,} \mathrm{2-thiophenyl,} \mathrm{etc.} \\
& \mathrm{Ar}^{\prime}=4-\mathrm{MeC}_{6} \mathrm{H}_{4}, 4-\mathrm{FC}_{6} \mathrm{H}_{4}, 4-\mathrm{EtOOCC}_{6} \mathrm{H}_{4}, 4-\mathrm{Me}_{2} \mathrm{NC}_{6} \mathrm{H}_{4} \text {, } \\
& 3-\mathrm{CF}_{3} \mathrm{C}_{6} \mathrm{H}_{4}, 2-\mathrm{NCC}_{6} \mathrm{H}_{4}, 2-\mathrm{BnOC}_{6} \mathrm{H}_{4}, 2-\mathrm{PhNHCOC}_{6} \mathrm{H}_{4} \text {, } \\
& \text { 4- } \mathrm{MeNHCOC}_{6} \mathrm{H}_{4}, 4-\mathrm{Et}_{2} \mathrm{NCOC}_{6} \mathrm{H}_{4}, 4-\mathrm{OHCC}_{6} \mathrm{H}_{4} \text {, etc. }
\end{aligned}
$$

图式 25 铁钛协同型结构类似的 Ar-M 间的氧化偶联反应

Scheme 25 Iron/titanate cooperatively oxidative coupling between Ar-M with similar stuctures

$\mathrm{X}$ 和 $\mathrm{C}\left(\mathrm{sp}^{3}\right)-\mathrm{X}$ 均可适用, 其中溴代芳杂环较溴代脂肪 烃更易发生偶联.

$$
\begin{aligned}
& 2 \mathrm{R}-\mathrm{Br} \underset{\mathrm{Mg}, \mathrm{THF}, \text { r.t. }}{\stackrel{5 \mathrm{~mol} \% \mathrm{Fe}(\mathrm{acac})_{3} \text { or } \mathrm{Fe}(\mathrm{DBM})_{3}}{4}} \begin{array}{r}
\mathrm{R}-\mathrm{R} \\
41 \% \sim 92 \% \text { yields }
\end{array} \\
& \mathrm{R}=\mathrm{Ph}, 4-\mathrm{MeOC}_{6} \mathrm{H}_{4}, 4-\mathrm{MeC}_{6} \mathrm{H}_{4}, 4-\mathrm{Me}_{2} \mathrm{NC}_{6} \mathrm{H}_{4}, 2-\mathrm{CF}_{3} \mathrm{C}_{6} \mathrm{H}_{4}, \mathrm{Bz} \text {, } \\
& \text { 2-thiophenyl, 2-naphthyl, Cy-, } n \text {-hexyl, etc. }
\end{aligned}
$$

同一时期, Sridev 等 ${ }^{[80]}$ 采用 $\mathrm{FeCl}_{3}$ 和 $\mathrm{Fe}_{3}(\mathrm{CO})_{12}$ 催化实现 了9-溴芴的自身还原偶联. 该反应不必添加还原剂即可 达到很高的收率. 研究发现, 若有 TEMPO 存在则反应 基本停止, 因此他们推测该反应经历自由基历程. 与氧 化偶联一样, 铁催化的交叉还原偶联也面临着底物自身 偶联副反应的干扰，迄今为止报道很少。2011 年, Wangelin 等 ${ }^{[81]}$ 报道了铁催化 $\mathrm{C}\left(\mathrm{sp}^{2}\right)-\mathrm{C}\left(\mathrm{sp}^{2}\right)$ 还原型交叉 偶联反应(Eq. 12). 采用简单的 $\mathrm{FeCl}_{3}$ /TMEDA 催化体系, 以 $\mathrm{Mg}$ 为还原剂, 即可直接将溴代芳烃和溴代烯烃偶联 生成苯乙烯类化合物. 该反应实质上可视为两步多米诺 反应: (1)铁催化溴代芳烃和镁预形成格氏试剂, (2)铁催 化溴代烯烃与格氏试剂的交叉偶联. 遗憾的是, 反应底 物只限于活泼溴代芳烃, 对于富电子的溴代芳杂环仍需 先制成格氏试剂再进行偶联. 尽管如此, 该方法作为铁 催化的多米诺反应在 $\mathrm{C}\left(\mathrm{sp}^{2}\right)-\mathrm{C}\left(\mathrm{sp}^{2}\right)$ 型偶联中的首次应 用, 为铁催化的碳一碳偶联提供了新思路.

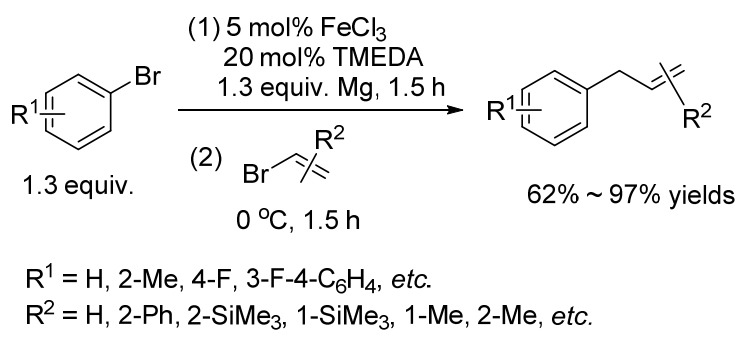

\section{3 铁催化 C一H 直接官能团化反应构建碳-碳} 键

\section{1 铁催化的直接烃基化反应}

与卤代烃和金属试剂的偶联反应相比, 通过 $\mathrm{C}-\mathrm{H}$
活化实现碳一碳偶联，一方面可以避免使用价格昂贵的 溴代和碘代烃; 另一方面，无需化学计量的金属制备金 属试剂，具有经济便捷、绿色环保的优势. 基于此，过渡 金属催化的 $\mathrm{C}-\mathrm{H}$ 活化反应刚问世，就深深地吸引了有 机合成工作者的目光. 迄今为止，人们已经报道了大量 采用 $\mathrm{Pd} 、 \mathrm{Ir} 、 \mathrm{Ru} 、 \mathrm{Pt}$ 等催化的 $\mathrm{C}-\mathrm{H}$ 活化反应 ${ }^{[82]}$. 近年 来, 铁催化的 $\mathrm{C}-\mathrm{H}$ 直接官能团化反应也越来越受到重 视. 早在 1987 年, 就曾有报道 $\mathrm{Fe}\left(\mathrm{PMe}_{3}\right)_{2} \mathrm{CNR}(\mathrm{R}=\mathrm{Me}$, $t$ - $\mathrm{Bu}, \mathrm{CH}_{3} \mathrm{CMe}_{3}, \mathrm{Ph}, 2,6$-xylyl)络合物在紫外光下可催化 异氰类化合物的直接芳基化反应 ${ }^{[83]}$.

2008 年, $\mathrm{Yu}$ 课题组 ${ }^{[84]}$ 报道了铁媒介下不活泼芳烃 的直接芳基化反应(Eq. 13). 该方法以芳基硼酸为芳基 化试剂, 具有良好的官能团耐受性. 遗憾的是, 反应需 要加入化学计量的 $\mathrm{Fe}_{2}\left(\mathrm{SO}_{4}\right)_{3}$. 虽然反应机理尚不明确, 但加入 TEMPO 后发现对反应无影响, 由此排除了反应 是自由基历程的可能性.

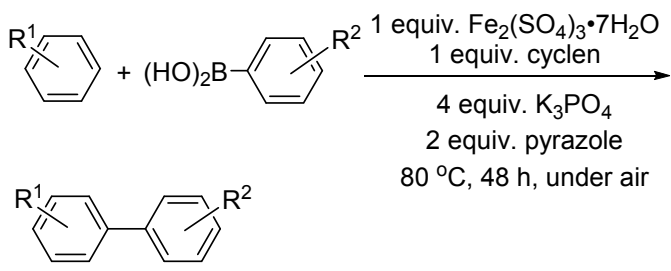

$31 \% \sim 83 \%$ yields

$\mathrm{R}^{1}=\mathrm{H}, 4-\mathrm{Me}, 4-\mathrm{Br}, 4-\mathrm{Cl}, 2,3-(\mathrm{Me})_{2}, 2,5-(\mathrm{Me})_{2}$, etc. $\mathrm{R}^{2}=\mathrm{H}, 2-\mathrm{Me}, 3-\mathrm{Br}, 4-\mathrm{Cl}, 4-\mathrm{COOEt}, 3-\mathrm{NO}_{2}, 4-\mathrm{COOH}$, etc. Cyclen $=1,4,7,10$-tetraazacyclododecane

在此基础上，该课题组 ${ }^{[85]}$ 采用大环多胺 $21 、 22$ 为 配体又实现了铁媒介下 $\mathrm{N}$-杂芳烃的直接芳基化反应 (Scheme 26).
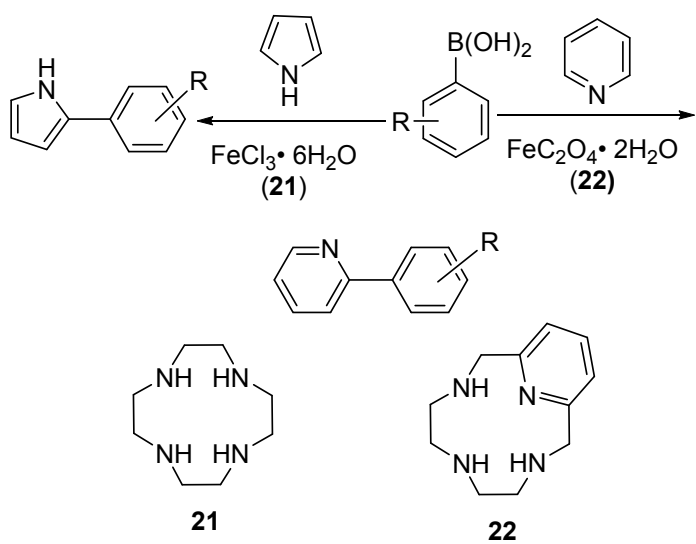

图式 26 铁催化 $N$-杂芳烃的直接芳基化反应 Scheme 26 Iron catalyzed direct arylation of N-heterocyclic compounds

2010 年, Lei 课题组 ${ }^{[87]}$ 首次采用卤代芳烃作为芳基 化试剂, 实现了铁催化不活泼芳烃的直接芳基化反应 
(Eq. 14). 该方法优点在于只需采用催化量的 $\mathrm{FeCl}_{3}$, 同 时氯代、溴代、碘代芳烃均可作为芳基化试剂. 值得注 意的是, 配体和碱的选择对收率影响很大. 底物为对溴 苯甲醚和苯时, 采用 TMEDA、联吡啶等配体和 $\mathrm{Na}_{2} \mathrm{CO}_{3}$ 、 $\mathrm{K}_{3} \mathrm{PO}_{4}$ 等无机碱均很难反应, 同时使用 DMEDA 和 LiHMDS 则收率可达 79\%.

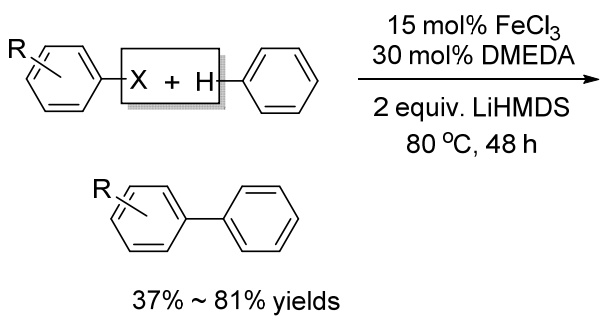

$\mathrm{R}=4-\mathrm{Me}, 2-\mathrm{MeO}, 4-t-\mathrm{Bu}, 4-\mathrm{Ph}_{2} \mathrm{~N}, 4-\mathrm{F}, 4-\mathrm{NC}$, etc. $\mathrm{X}=\mathrm{Cl}, \mathrm{Br}, \mathrm{I}$

DMEDA = N,N'-dimethylethane-1,2-diamine $\mathrm{HMDS}=$ hexamethyldisilazane

Deb 等 ${ }^{[8]}$ 同样采用芳基嗍酸为芳基化试剂, 实现了 铁催化 $\mathrm{N}$-杂芳烃的 $\mathrm{C}-\mathrm{H}$ 直接芳基化反应. 多数 $N$-杂芳 烃如吡啶、喹啉、喹噁啉、苯并噻唑、邻菲洛啉等均可 反应. 芳基化一般发生在 $\mathrm{N}$ 原子的邻位, 但在喹啉和邻 菲洛啉的 4-位 $\mathrm{C}-\mathrm{H}$ 上也能实现.

同一时期，Vallée 等 ${ }^{[88}$ 也报道了碘代芳烃作为芳基 化试剂的 $\mathrm{C}-\mathrm{H}$ 活化反应. 其中的催化剂为 $\mathrm{Fe}(\mathrm{OAc})_{2}$, 配体选用 4,7-二苯基-1,10-邻菲咯啉, 叔丁醇钾为碱. 在 实验中发现, 当以甲苯为底物时, 得到甲基邻、间、对 位芳基化产物的混合物, 在体系中加入 TEMPO 能抑制 反应的进行. 由此他们推测, 反应经历自由基历程, 首 先由 $\mathrm{Fe}$ (II)与碘代烃经单电子氧化生成活性自由基 $\mathbf{2 3}$, 23 对芳烃进行自由基加成形成中间体 24, 随后脱 $\mathrm{H}$ 得 到联芳烃(Scheme 27).

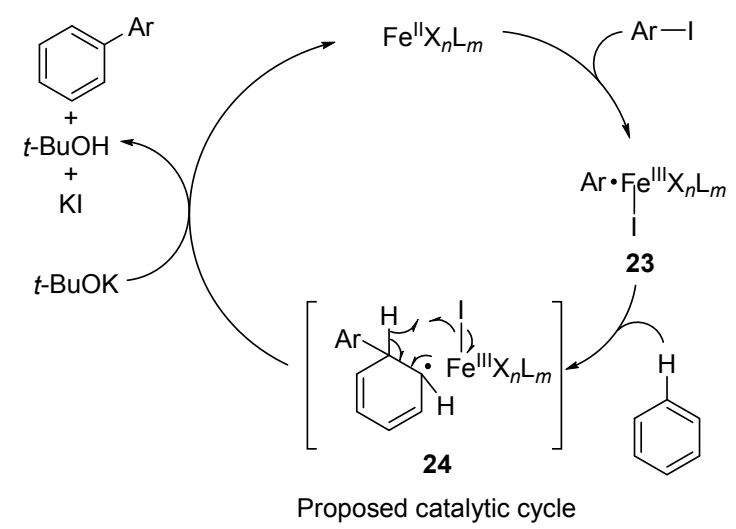

图式 27 碘代芳烃作为芳基化试剂

Scheme 27 Aryl iodides act as arylation reagents

值得一提的是, 铁催化的氧化型 $\mathrm{C}-\mathrm{H}$ 直接烃基化 反应, 近来也日益受到人们的重视. 这类反应常使用大
过量的金属试剂(一方面作碱，另一方面用作偶联试剂), 在过渡金属催化体系和氧化剂的作用下进行偶联, 在一 些特定底物体系中如 Schiff 碱邻位的 C- $\mathrm{H} 、 N$-杂菲的 10-位 $\mathrm{C}-\mathrm{H}$ 等都获得了很好的结果. 如 Nakamura 等 ${ }^{[89]}$ 在 2008 年报道了 $\mathrm{Fe}$ 催化下 2-芳基吡啶与 $N$-杂菲的氧 化型 $\mathrm{C}-\mathrm{H}$ 直接芳基化反应等(Scheme 28). 该课题组 ${ }^{[90]}$ 同样也报道了 Schiff 碱邻位的 $\mathrm{C}-\mathrm{H}$ 直接芳基化反应 (Scheme 28). 在这些反应中, 需要加入 6 equiv.的金属 试剂, 以 $\mathrm{Fe}(\mathrm{acac})_{3}$ 作催化剂, 邻菲洛啉或联吡啶作配体, 2,4-二氯异丁烷为氧化剂. 采用氧气作为氧化剂同样能 取得优良的收率 ${ }^{[1]}$.

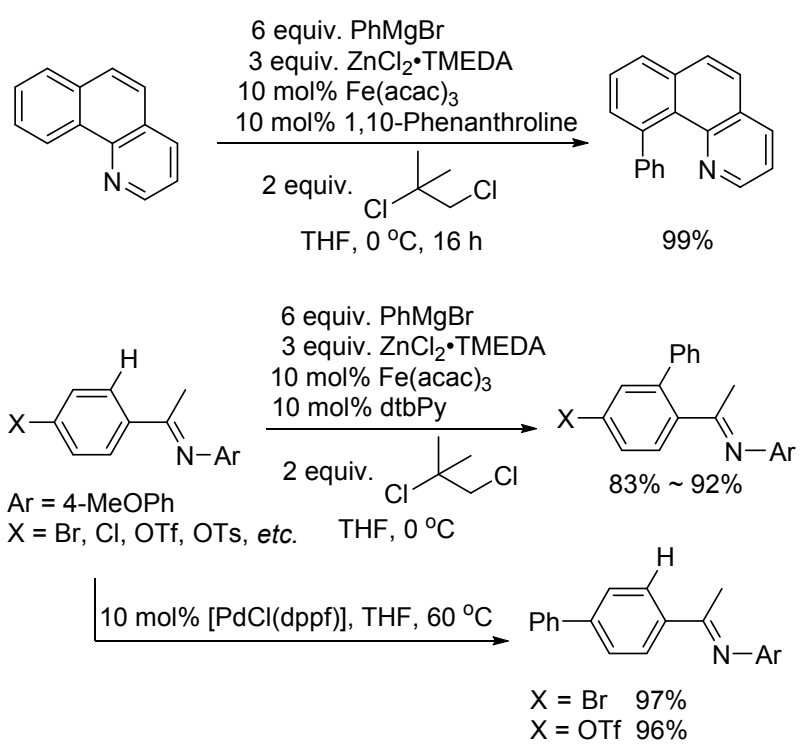

图式 28 铁催化氧化型直接芳基化反应

Scheme 28 Iron catalyzed oxidative direct arylation

2011 年, 该课题组 ${ }^{[92]}$ 对以上反应进行了改进. 采用 氯苯作为共溶剂, 以格氏试剂替代锌试剂并通过缓慢滴 加的方法使金属试剂用量降至 2.4 equiv., 他们推测, 缓 慢滴加格氏试剂减缓了活性铁物种的形成, 而氯苯可以 作为配体稳定该物种, 因此在减少金属试剂的情况下反 应能取得优良的收率.

2012 年, 该课题组 ${ }^{[93]}$ 又报道了以溴代芳烃为底物, 采用镁屑为媒介实现了铁催化下 $N$-杂菲 10-位的直接芳 基化反应(Eq. 15). 反应成功的关键在于采用 $\mathrm{THF} / 1,4-$ 二氧六环混合溶剂. 与之前的反应相比，该方法适用范 围更广, 并且底物和催化剂用量都大为减少.

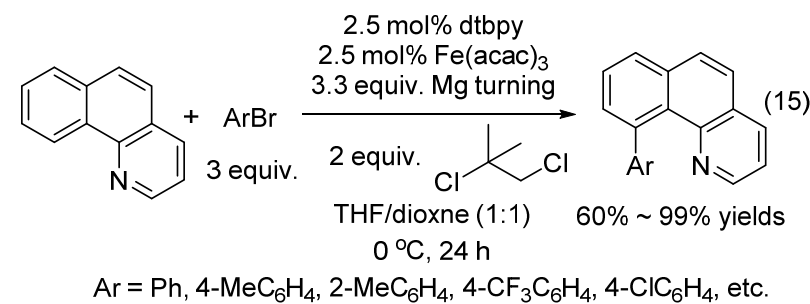


除了 $\mathrm{sp}^{2}$ 杂化的 $\mathrm{C}-\mathrm{H}$ 键外, $\mathrm{sp}^{3}$ 杂化 $\mathrm{C}-\mathrm{H}$ 键的直接 烃基化反应同样受到人们的关注. 2013 年, Nakamura 课 题组 ${ }^{[94]}$ 报道了铁催化 $\mathrm{C}\left(\mathrm{sp}^{3}\right)-\mathrm{H}$ 的直接芳基化反应 (Scheme 29). 在 $\mathrm{Fe}(\mathrm{acac})_{3}$ 的催化下, 底物 25 中的 8-喹 啉胺基团可作为导向基, 与 $\mathrm{Fe}$ 催化剂形成稳定的有机 铁中间体 26, 因此 $\beta$ 位甲基的比苄基优先发生 $\mathrm{C}-\mathrm{H}$ 活 化，从而实现对甲基 $\mathrm{C}-\mathrm{H}$ 的活化.

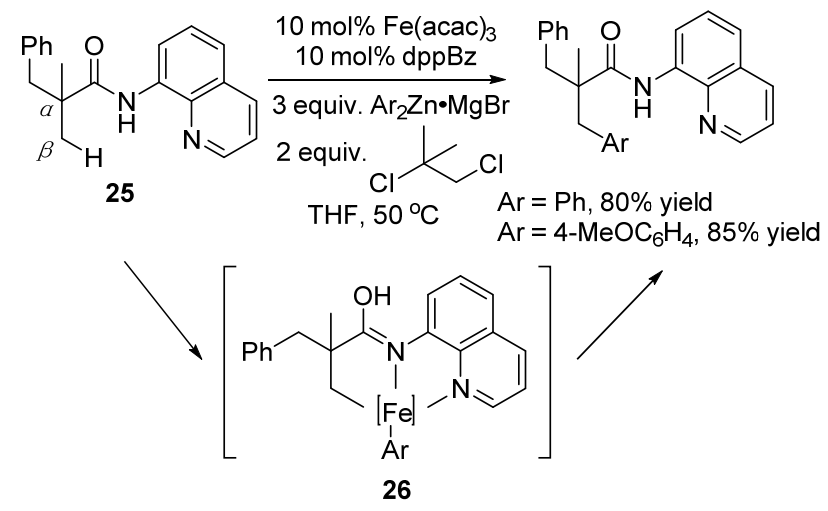

图式 29 铁催化 $\mathrm{C}\left(\mathrm{sp}^{3}\right)-\mathrm{H}$ 键的直接烃基化反应 Scheme 29 Iron catalyzed direct arylation of $\mathrm{C}\left(\mathrm{sp}^{3}\right)-\mathrm{H}$ bond

在此基础上, 该课题组 ${ }^{[95]}$ 采用双膦配体 27 代替 $\mathrm{dppBz}$, 并以 2,3-二氯丁烷为氧化剂, 实现了对 $\mathrm{C}\left(\mathrm{sp}^{2}\right)$ $\mathrm{H}$ 和 $\mathrm{C}\left(\mathrm{sp}^{3}\right)-\mathrm{H}$ 的直接甲基化反应(Scheme 30). 底物可 以为含 8-喹啉胺基或吡啶-2-甲酰基的芳基、烯基和烷基 酰胺. 值得注意的是, 反应采用的烷基化试剂为 $\mathrm{AlMe}_{3}$ 及其胺基络合物, 相比格氏试剂和锌试剂更温和, 可有 效避免对铁催化剂的还原, 增加催化循环次数.

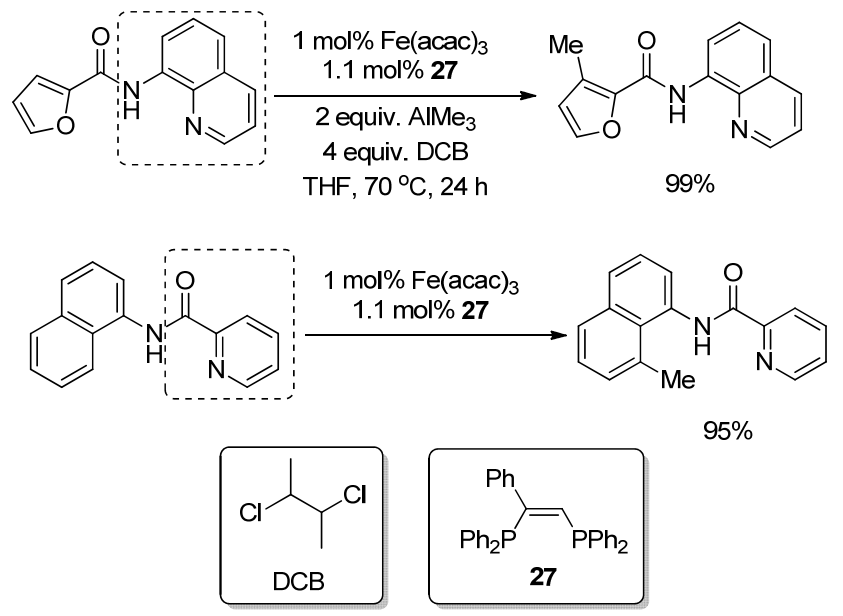

图式 30 铁催化的直接甲基化反应

Scheme 30 Iron catalyzed direct methylation reaction

近期，该课题组 ${ }^{[96]}$ 报道了铁催化芳基羧酸、酯、酰 胺和芳基酮的邻位 $\mathrm{C}-\mathrm{H}$ 直接甲基化反应(Eq. 16). 该反 应突破了以往底物分子需含有邻位导向基的限制, 采用
简单的芳香羰基化合物即可实现邻位 $\mathrm{C}-\mathrm{H}$ 功能化，极 大地丰富了铁催化 $\mathrm{C}-\mathrm{H}$ 活化的合成策略. 反应成功的 关键在于使用 $\mathrm{AlMe}_{3}$ 为甲基化试剂的同时还采用了三 齿配体 28.

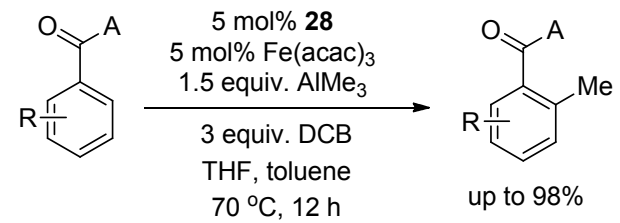

$A=O H, O R ', N(H) R^{\prime}, R^{\prime}$, etc.

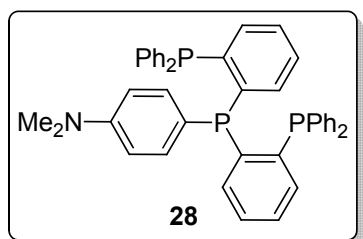

\section{2 铁催化交叉脱氢偶联反应}

以上工作均为采用有机金属试剂或卤代烃为直接 烃基化试剂, 实现 $\mathrm{C}-\mathrm{H}$ 键与 $\mathrm{C}-\mathrm{X}$ 键或 $\mathrm{C}-\mathrm{M}$ 键的偶 联. 相比之下, 两个 $\mathrm{C}-\mathrm{H}$ 键的直接偶联更高效和环保. 因此，过渡金属催化的交叉脱氢偶联反应(CDC 反应)日 益受人重视. 2007 年, $\mathrm{Li}$ 课题组 ${ }^{[97]}$ 首次报道了铁催化的 $\mathrm{CDC}$ 反应 $(\mathrm{Scheme} 31)$. 采用 $\mathrm{FeCl}_{2}$ 为催化剂, $(t-\mathrm{BuO})_{2}$ 为 氧化剂, $80{ }^{\circ} \mathrm{C}$ 下通过对苄基的 $\mathrm{C}-\mathrm{H}$ 活化实现了二苯甲 烷与 1,3-二羰基化合物的偶联. 作者推测反应经历单电 子转移(SET)过程: 首先 $(t-\mathrm{BuO})_{2}$ 在 $\mathrm{FeCl}_{2}$ 作用下形成 $t$ - $\mathrm{BuO}$ 自由基 29, 后者活化芐基使之形成苄基自由基 30, 与同时形成的 $\mathrm{Fe}(\mathrm{III})$ 中间体 $\mathbf{3 1}$ 反应生成产物 $\mathbf{3 2}$ (Scheme 31).

2009 年, Shi 课题组 ${ }^{[8]}$ 报道了首例铁催化两种不同 类型的 $\mathrm{C}-\mathrm{H}$ 键同时被活化进行交叉偶联反应(Scheme 32). 在该反应中，富电子的芳烃和茮基同时发生活化， 发生 $\mathrm{C}\left(\mathrm{sp}^{2}\right)-\mathrm{C}\left(\mathrm{sp}^{3}\right)$ 偶联. 一般情况下, $\mathrm{CDC}$ 反应直接使 用大过量的二芳基甲烷，既作反应物又作溶剂. 在该反 应中采用 DCE 作为溶剂, 使二苯甲烷的用量大为减少. 同时以 DDQ 代替过氧化物作为氧化剂不仅效果更好, 安全性也更高. 对于反应的机理, 他们推测首先铁催化 下苠基通过单电子氧化形成茮基自由基 33, 后者再被 氧化为苄基阳离子 35, 与芳烃发生 Friedel-Crafts 型反应 生成中间体 36, 随即脱氢得到产物 37.

与苠基的 $\mathrm{C}-\mathrm{H}$ 相比，普通的 $\mathrm{C}\left(\mathrm{sp}^{3}\right)-\mathrm{H}$ 活性很低， 因此对其进行 $\mathrm{C}-\mathrm{H}$ 活化更具挑战性. 迄今为止，只有 一例 ${ }^{[99]}$ 铁催化的不活泼 $\mathrm{C}\left(\mathrm{sp}^{3}\right)-\mathrm{H}$ 活化(Eq. 17). 反应采 用 $\mathrm{FeCl}_{2} \bullet 4 \mathrm{H}_{2} \mathrm{O}$ 为催化剂, $(t-\mathrm{BuO})_{2}$ 为氧化剂, 在较剧烈 的条件下 $\left(100{ }^{\circ} \mathrm{C}\right)$, 实现了环烷烃与 1,3 -二羰基化合物 的 $\mathrm{CDC}$ 反应. 


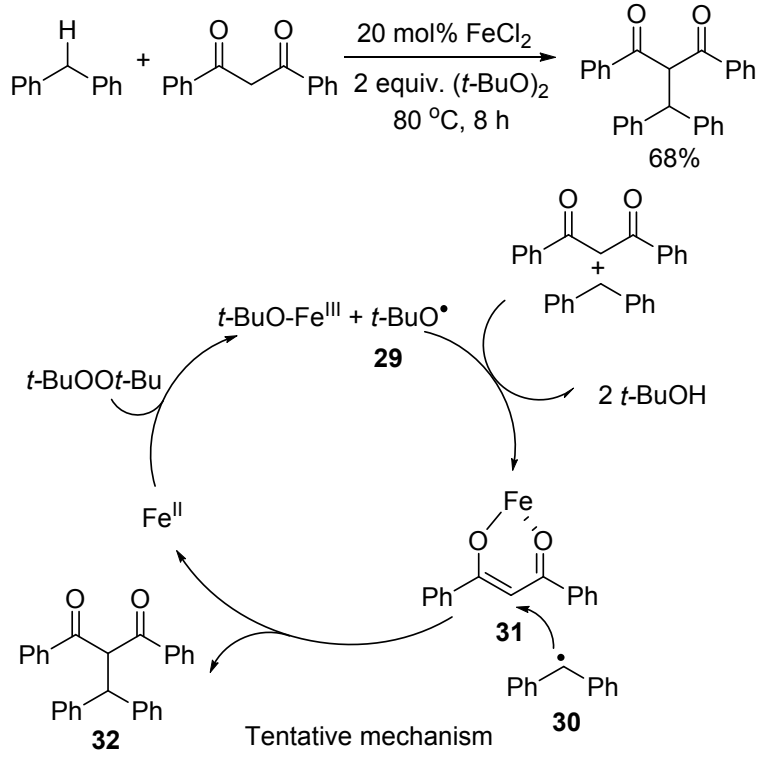

图式 31 铁催化的 $\mathrm{CDC}$ 反应

Scheme 31 Iron catalyzed CDC reaction

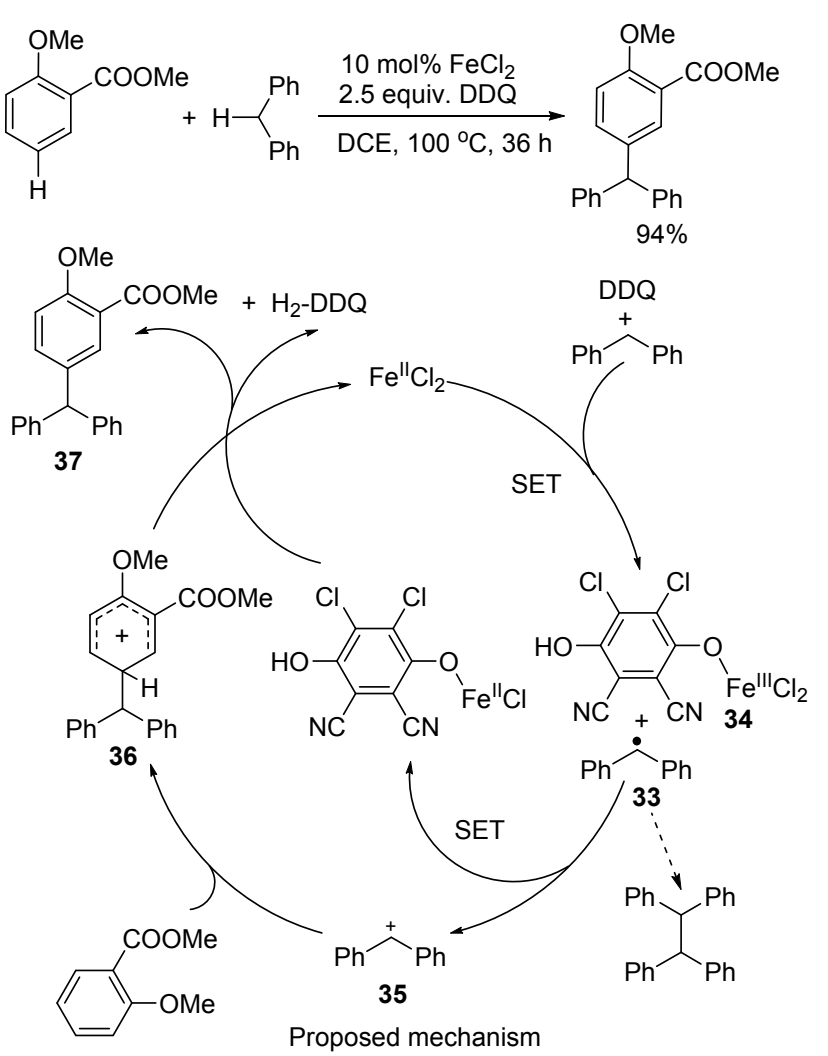

图式 32 铁催化不同类型 $\mathrm{C}-\mathrm{H}$ 键的 $\mathrm{CDC}$ 反应

Scheme 32 Iron catalyzed $\mathrm{CDC}$ reaction of different $\mathrm{C}-\mathrm{H}$ bonds

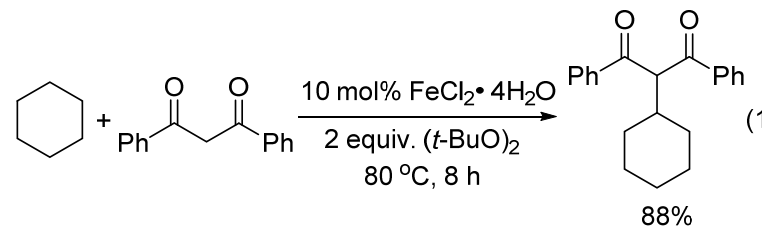

当 $\mathrm{C}\left(\mathrm{sp}^{3}\right)-\mathrm{H}$ 邻位为杂原子如 $\mathrm{N} 、 \mathrm{O} 、 \mathrm{~S}$ 等时，能促 进其在铁催化下发生 $\mathrm{C}-\mathrm{H}$ 活化. 在 2008 年, $\mathrm{Li}$ 课题 组 ${ }^{[100]}$ 报道了氮杂、氧杂和硫杂的脂肪烃杂原子邻位的 $\mathrm{C}-\mathrm{H}$ 活化(Eq. 18). 与苄基的 $\mathrm{C}-\mathrm{H}$ 活化相比，该反应 需要加入较多的 $(t-\mathrm{BuO})_{2}$, 使用 $\mathrm{Fe}(\mathrm{CO})_{9}$ 代替 $\mathrm{FeCl}_{2}$ 效果 更佳.

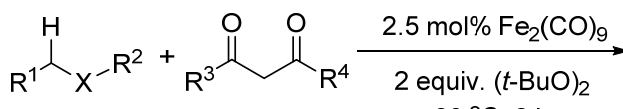

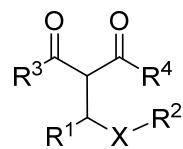

$$
\begin{aligned}
& 80^{\circ} \mathrm{C}, 8 \mathrm{~h}
\end{aligned}
$$

2009 年，该课题组 ${ }^{[101]}$ 又报道了一例亚甲基的直接 双烷基化反应(Eq. 19). 一分子的 $N, N$-二甲基苯胺与两 分子的 1, 3-二羰基化合物在 $\mathrm{Fe}(\mathrm{CO})_{9}$ 的催化下发生 $\mathrm{CDC}$ 反应生成亚甲基桥联的双 1,3-二羰基化合物.

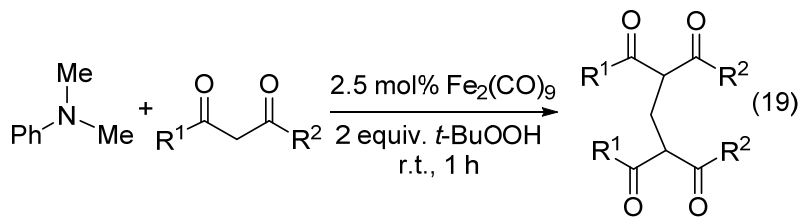

$\mathrm{Liu}$ 等 ${ }^{[102]}$ 对甘氨酸衍生物的胺基 $\alpha$-位实行 $\mathrm{C}-\mathrm{H}$ 活 化，继而与炔发生氧化偶联生成喹啉衍生物(Eq. 20). 在 此之前, 氨基酸的衍生化主要依赖于克莱森重排、紫外 光解和强碱脱质子等 ${ }^{[103]}$ ，与之相比，该方法在原子经 济性和环境友好方面显然更具优势.

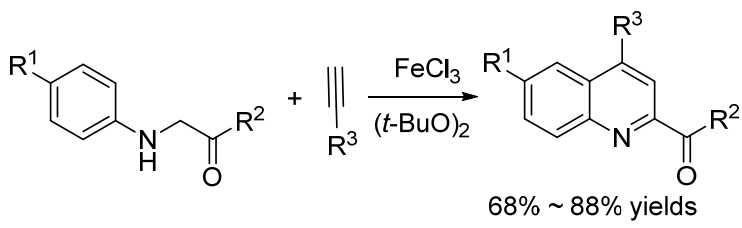

2010 年, Nakamura 课题组 ${ }^{[104]}$ 在研究铁催化 $\mathrm{Ph}_{2} \mathrm{Zn}$ 和对甲碘苯的偶联时意外地得到 2-苯基四氢呋喃. 作者 认为，在铁催化下碘代芳烃可以产生芳基自由基，对四 氢呋喃的 2-位进行 $\mathrm{C}-\mathrm{H}$ 活化，进而与金属试剂偶联. 受此启发，该课题组报道了脂肪胺的 $\alpha$-位直接芳基化反 应. 首先底物 38 中的 $N$-IBn (IBn 为 2-碘苄基)在铁催化 下形成芳基自由基 39, 随即发生 1,5-H 转移形成 40, 使 胺的 $\alpha$-位 $\mathrm{C}-\mathrm{H}$ 活化, 生成中间体 41 后进行还原消除得 到 $\alpha$-取代脂肪胺 42 (Scheme 33).

2011 年, Qian 等 ${ }^{[105]}$ 使用 $\mathrm{Fe}(\mathrm{OAc})_{2}$ 催化实现了 2-取 代 $N$-杂芳烃与 $N$-磺酰亚胺的偶联. 反应经历亲核加成 与 $\mathrm{E} 2$ 消除历程, 首先 $N$-磺酰亚胺 44 与催化剂形成的金 属一烯胺对 43 进行亲核加成形成 45 , 后者的 $\mathrm{C}\left(\mathrm{sp}^{3}\right)-\mathrm{H}$ 在催化剂作用下被活化，伴随 NHTs 基团的离去, C- $\mathrm{H}$ 
<smiles>Ic1ccccc1CN1CCCC1</smiles>

38<smiles>[3H][Te]</smiles><smiles>O=C(Br)c1ccccc1CN1CCCC1</smiles>

图式 33 铁催化脂肪胺的 $\alpha$-位直接芳基化

Scheme 33 Iron catalyzed $\alpha$-arylation of aliphatic amine

和 $\mathrm{C}-\mathrm{N}$ 同时断裂, 形成 $\mathrm{C}=\mathrm{C}$ 键( Scheme 34).

$$
\begin{aligned}
& R \frac{1}{2}=- \\
& \mathrm{Fe}(\mathrm{OAc})_{2} \sqrt{\mathrm{R}^{2} \mathrm{CH}=\mathrm{NTs}(44)} \begin{array}{c}
\text { Nucleophilic addition } \\
43
\end{array}
\end{aligned}
$$$$
\text { }
$$

45

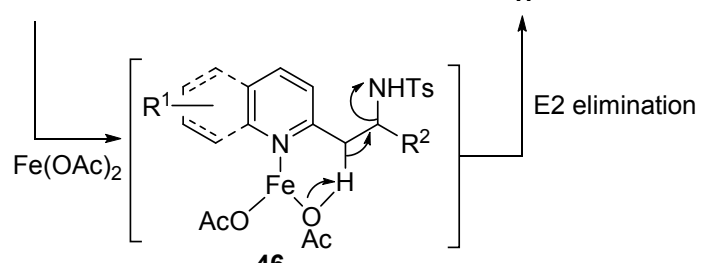

46

图式 34 铁催化 $N$-杂芳烃的直接烯基化反应

Scheme 34 Iron catalyzed direct alkenylation of N-heterocyclic compounds

Volla 等 ${ }^{[106]}$ 报道了铁催化的叔胺与末端炔的氧化型 $\mathrm{C}-\mathrm{H}$ 活化反应. 该方法的优点在于无需添加任何配体 和溶剂, 即可完成叔胺和末端炔的 $\mathrm{C}-\mathrm{H}$ 活化及偶联. 反应对脂肪炔和芳基炔均适用，采用三乙基硅保护的末 端炔烃可实现与不同类型叔胺的选择性偶联(Scheme $35)$.

2011 年, Chandrasekharam 等 ${ }^{[107]}$ 采用过氧化叔丁醇 为氧化剂, 实现了等物质的量的 $N$-取代芳胺和酚类化 合物间的 CDC 反应(Eq. 21). 脱氢偶联选择性地发生在 $N$-取代胺基和酚羟基的邻位，这一反应为构建多官能团 类联芳烃提供了一种新途径.

$\mathrm{Li}$ 课题组 ${ }^{[108]}$ 也报道了苯酚羟基邻位的脱氢偶联. 苯酚与 $\beta$-酮酸酯在铁催化下发生 $\mathrm{CDC}$ 反应生成化合物 48, 随即发生互变异构形成 49, 缩合得到多取代苯并呋

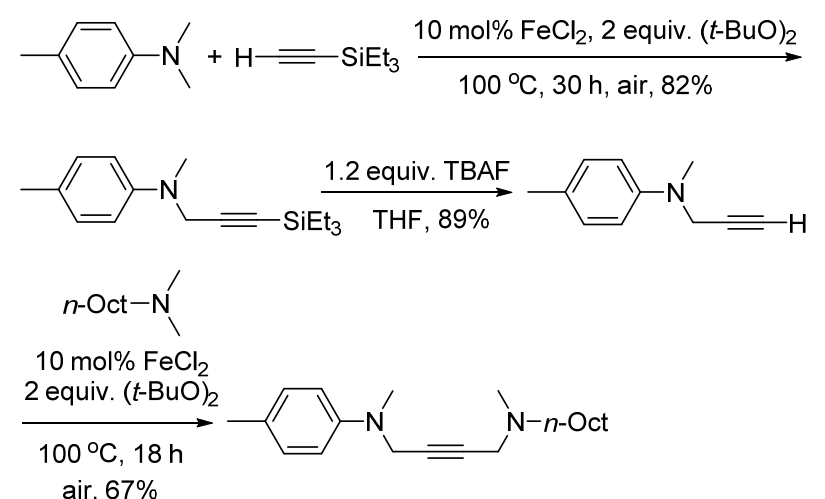

图式 35 铁催化叔胺与末端炔的 CDC 反应

Scheme 35 Iron catalyzed CDC reaction between tertiary amine with terminal alkyne

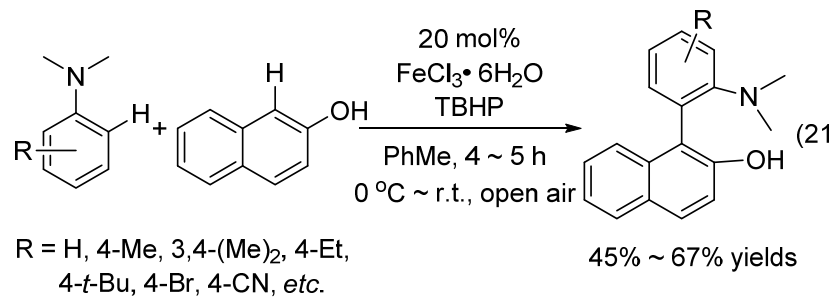

喃 50 (Scheme 36). 研究发现, 改变铁盐的种类对反应 影响不大. 但铁盐中的水对反应有促进作用, 如果在体 系中加入 $4 \AA$ 分子篮除水, 将使反应终止.

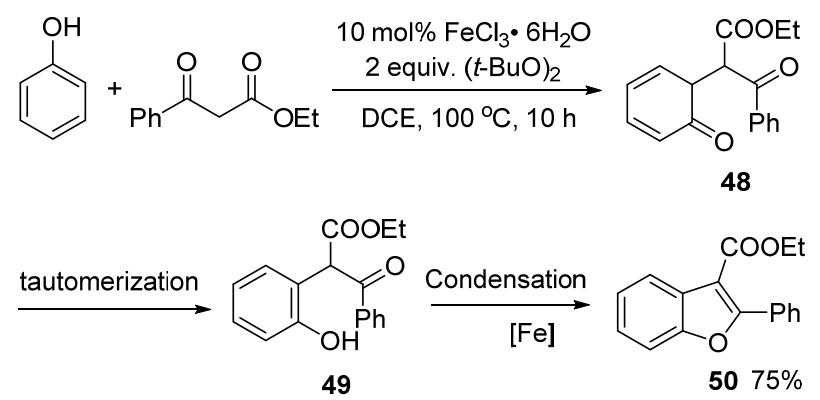

图式 36 铁催化酚的 $\mathrm{CDC}$ 反应

Scheme 36 Iron catalyzed CDC reacton of phenol

\section{3 铁催化重氮化合物对 $\mathrm{C}-\mathrm{H}$ 键的插入反应构建碳- 碳键}

此外，过渡金属催化卡宾对 $\mathrm{C}-\mathrm{H}$ 键的插入反应 ${ }^{[109]}$ 也是一种有效的 $\mathrm{C}-\mathrm{H}$ 直接官能团化手段. 其中, 重氮 化合物在过渡金属催化下能形成金属一卡宾中间体，进 而实现对 $\mathrm{C}-\mathrm{H}$ 键的插入. 由于在反应过程中只脱去一 分子 $\mathrm{N}_{2}$, 这一方法具有原子经济性和绿色环保的优势. 迄今为止, 该类反应使用最广泛的为双铑(II)催化剂. 近年来研究发现，铁催化剂在该类反应中也表现出较好 的催化性能 ${ }^{[110]}$. 
在 2002 年, Che 课题组 ${ }^{[11]}$ 报道了采用重氮化合物 51 和化学计量的铁-卟啉络合物 52 制备新型铁-卡宾络 合物 53. 53 在 $60 \sim 80{ }^{\circ} \mathrm{C}$ 下能顺利实现对饱和 $\mathrm{C}-\mathrm{H}$ 键 的插入反应(Scheme 37). 尽管反应只局限于对烯丙型、 芐基型和四氢呋喃 2-位等相对活泼的 $\mathrm{C}-\mathrm{H}$ 键, 该研究 为铁催化 $\mathrm{C}-\mathrm{H}$ 活化提供了一条新途径.

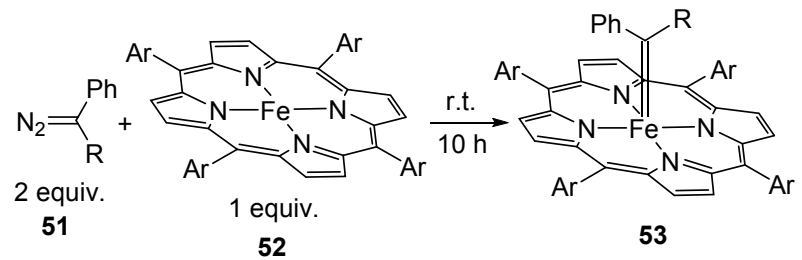

$\mathrm{R}=\mathrm{Ph}, \mathrm{COOEt}, \mathrm{CO}_{2} \mathrm{CH}_{2} \mathrm{CH}=\mathrm{CH}_{2} ; \mathrm{Ar}=\mathrm{C}_{6} \mathrm{~F}_{5}$

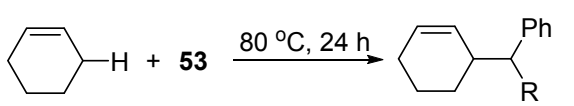

$1 \mathrm{~mL} \quad 0.015 \mathrm{mmol} \quad \mathrm{R}=\mathrm{CO}_{2} \mathrm{Et} 64 \%$ yield

图式 37 铁催化重氮化合物对 $\mathrm{C}\left(\mathrm{sp}^{3}\right)-\mathrm{H}$ 键的插入反应 Scheme 37 Iron catalyzed $\mathrm{C}-\mathrm{H}$ insertion reaction of $\mathrm{C}\left(\mathrm{sp}^{3}\right)-\mathrm{H}$ bond with diazo compounds

2008 年, Mbuvi 等 ${ }^{[112]}$ 的研究将铁-卟啉的用量降至 1 2 $\mathrm{mol} \%$, 实现了铁催化重氮化合物对 $\mathrm{C}-\mathrm{H}$ 键的插 入(Eq. 22). 值得一提的时, 当使用均三甲苯为底物时, 同时得到苄基 $\mathrm{C}-\mathrm{H}$ 和苯环 $\mathrm{C}-\mathrm{H}$ 插入产物, 说明该方 法不仅能实现 $\mathrm{C}\left(\mathrm{sp}^{3}\right)-\mathrm{H}$ 的功能化, 对 $\mathrm{C}\left(\mathrm{sp}^{2}\right)-\mathrm{H}$ 同样有 效.

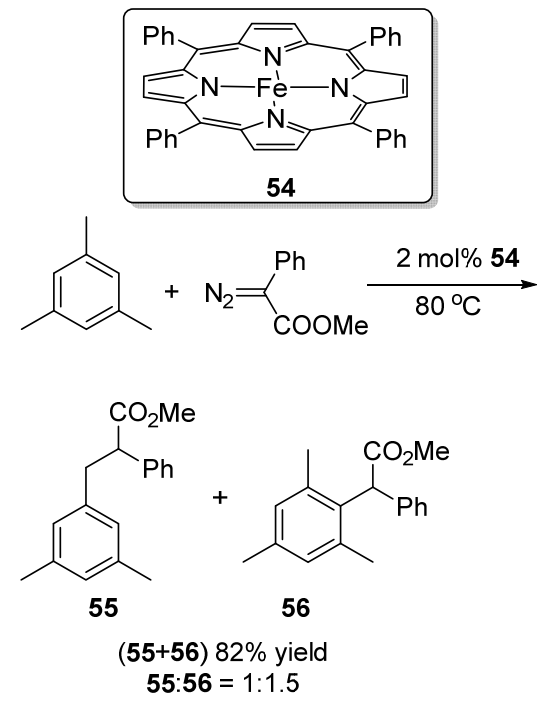

2011 年, Zhou 课题组 ${ }^{[113]}$ 采用 $\mathrm{Fe}\left(\mathrm{ClO}_{4}\right)_{2}$ 、TMEDA 和四 [3,5-二(三氟甲基)苯基]嗍酸钠(57)形成的配合物, 实现了铁催化重氮化合物对吲哚的 $\mathrm{C}-\mathrm{H}$ 插入反应 (Scheme 38). 上例中 Mbuvi 的方法虽然也能对 $\mathrm{C}\left(\mathrm{sp}^{2}\right)$ $\mathrm{H}$ 进行插入, 但伴随着 $\mathrm{C}\left(\mathrm{sp}^{3}\right)-\mathrm{H}$ 插入和重排的副反应.
在此基础上, 采用一类新型的手性螺环双噁唑啉 58 代 替 TMEDA, 在不对称 $\mathrm{C}-\mathrm{H}$ 插入反应中显示出优异的 立体选择性. 近期, 该课题组 ${ }^{[114]}$ 采用 1,10 -邻二氮菲代 替 TMEDA，将底物适用范围拓展至富电子芳烃，使铁 催化重氮化合物的 $\mathrm{C}-\mathrm{H}$ 插入反应得到了极大的丰富 (Scheme 38).

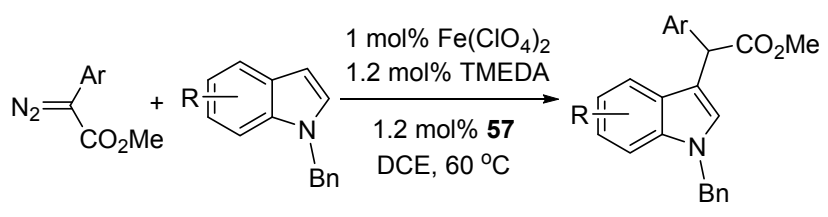

$72 \% \sim 95 \%$

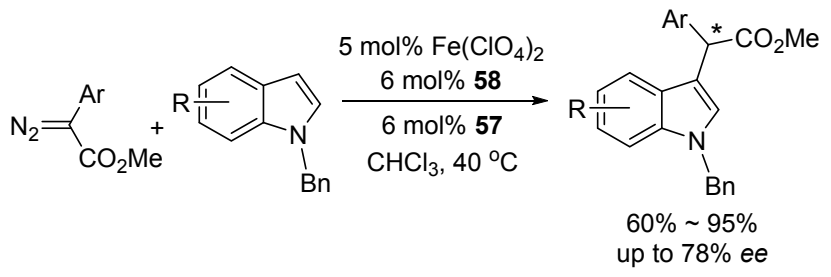<smiles>COC(=O)C(=[N+])c1ccccc1</smiles><smiles>FC(F)(F)c1cc(B(c2cc(C(F)(F)F)cc(C(F)(F)F)c2)c2cc(C(F)(F)F)cc(C(F)(F)F)c2)cc(C(F)(F)F)c1</smiles><smiles></smiles>

58

图式 38 铁催化重氮化合物对 $\mathrm{C}\left(\mathrm{sp}^{2}\right)-\mathrm{H}$ 键的插入反应 Scheme 38 Iron catalyzed $\mathrm{C}-\mathrm{H}$ insertion reaction of $\mathrm{C}\left(\mathrm{sp}^{2}\right)-$ $\mathrm{H}$ bond with diazo compounds

\section{4 总结与展望}

铁催化的碳-碳偶联反应研究自 20 世纪 90 年代进 入 “快车道” 以来, 迄今为止已得到极大的发展. 人们 对铁催化卤代烃、磺酸酯、磷酸酯、硫梄等亲电试剂和 格氏试剂、锌试剂、嗍试剂、铜试剂等亲核试剂的偶联 反应，以及铁催化的氧化偶联、还原偶联和 $\mathrm{C}-\mathrm{H}$ 直接 官能团化反应进行了大量研究，探索出不少条件温和、 高效、高选择性的催化体系，相关的机理被提出并不断 被完善.

铁催化的碳一碳偶联反应取得了很多成果的同时也 面临着许多问题: (1)目前对铁催化 $\mathrm{C}\left(\mathrm{sp}^{2}\right)-\mathrm{C}\left(\mathrm{sp}^{3}\right)$ 偶联 的研究最多. 相比之下, 其它类型的偶联反应还需进一 步完善. 如 $\mathrm{C}\left(\mathrm{sp}^{2}\right)-\mathrm{C}\left(\mathrm{sp}^{2}\right)$ 偶联中如何避免底物的自身 
偶联副反应仍是一大挑战; (2)适用铁催化的金属试剂种 类仍需拓展. 与铁催化格氏试剂的 Kumada 反应和锌试 剂的 Negishi 反应相比, 铁催化嗍试剂的 Suzuki 反应和 锡试剂的 Stille 反应的例子很少; (3)对铁催化碳一碳偶联 反应的机理有待深入研究. 目前对 $\mathrm{Fe}$ 在催化循环中的 价态变化倾向于 $\mathrm{Fe}(\mathrm{III}) / \mathrm{Fe}(\mathrm{I})$ 和 $\mathrm{Fe}(\mathrm{II} / 0)$ 两种, 如何确定 $\mathrm{Fe}$ 的最低氧化态并分离出相关中间体是未来的研究重 点之一. 总而言之, 铁催化的碳一碳偶联反应机遇与挑 战并存. 采用廉价、绿色的铁催化剂实现更多高效、高 选择性的偶联反应对于促进工业化生产和绿色化学的 发展任重道远.

\section{References}

[1] (a) De Mejiere, A.; Diederich, F. Metal-Catalyzed Cross-Coupling Reactions, Wiley-VCH, Weinheim, 2004.

(b) Hartwig, J. F. Organotransition Metal Chemistry, University Science Books, Sausalito, California, 2010.

(c) Liu, C.; Zhang, H.; Shi, W.; Lei, A. W. Chem. Rev. 2011, 111, 1780 .

[2] (a) Graening, T.; Schmalz, H.-G. Angew. Chem., Int. Ed. 2003, 42, 2580 .

(b) Nicolaou, K. C.; Bulger, P. G.; Sarlah, D. Angew. Chem., Int. Ed. 2005, 44, 4490.

(c) Magano, J.; Dunetz, J. R. Chem. Rev. 2011, 111, 2177.

[3] (a) Wu, X.-F.; Anbarasan, P.; Neumann, H.; Beller, M. Angew. Chem., Int. Ed. 2010, 49, 9047.

(b) Chen, X.; Engle, K. M.; Wang, D.-H.; Yu, J.-Q. Angew. Chem., Int. Ed. 2009, 48, 5094.

[4] Van Leeuwen, P. N. M.; Kamer, P. C. J.; Claver, C.; Pamies, O.; Dieguez, M. Chem. Rev. 2011, 111, 2077.

[5] For recent reviews, see:

(a) Song, Y.; Tang, X. S.; Hou, X. M.; Bai, Y. J. Chin. J. Org. Chem. 2013, 33, 76 (in Chinese).

(宋阳, 唐雪松, 侯晓萌, 白银娟, 有机化学, 2013, 33, 76.)

(b) Riener, K.; Haslinger, S.; Raba, A.; Högerl, M. P.; Cokoja, M.; Herrmann, W. A.; Kühn. F. E. Chem. Rev. 2014, 114, 5215.

[6] (a) Bolm, C.; Legros, J.; Paih, J. L.; Zani, L. Chem. Rev. 2004, 104, 6217.

(b) Gopalaiah. K. Chem. Rev. 2013, 113, 3248.

(c) Bauer, I.; Knölker, H.-J. Chem. Rev. 2015, 115, 3170.

(d) Guo, N.; Zhu, S. F. Chin. J. Org. Chem. 2015, 35, 1383 (in Chinese).

(郭娜, 朱守非, 有机化学 2015, 35, 1383.)

[7] (a) Bolm, C.; Legros, J.; Le Paih, J.; Zani, L. Chem. Rev. 2004, 104, 6217.

(b) Plietker, B. Iron Catalysis in Organic Chemistry: Reactions and Applications, Wiley-VCH, Weinheim, 2008.

(c) Sherry, B. D.; Fürstner, A. Acc. Chem. Res. 2008, 41, 1500.

(d) Fürstner, A. Angew. Chem., Int. Ed. 2009, 48, 1364.

(e) Cahiez, G.; Moyeux, A. Chem. Rev. 2010, 110, 1435.

[8] (a) Wang, C.; Fu, Y.; Liu, L.; Guo, Q. X. Chin. J. Org. Chem. 2007, 27, 703 (in Chinese).

(王晨, 傅尧, 刘否, 郭庆祥, 有机化学, 2007, 27, 703.)

(b) Nakamura, E.; Yoshikai, N. J. Org. Chem. 2010, 75, 6061.

[9] Kharasch, M. S.; Fields, E. K. J. Am. Chem. Soc. 1941, 63, 2316.

[10] (a) Kochi, J. K. J. Am. Chem. Soc. 1971, 93, 1487.

(b) Kochi, J. K. J. Org. Chem. 1976, 41, 599.
[11] Walborsky, H. M. J. Org. Chem. 1981, 46, 5074.

[12] Molander, G. A. Tetrahedron Lett. 1983, 24, 5449.

[13] (a) Cahiez, G. Synthesis 1998, 1199.

(b) Cahiez, G. Synlett 2001, 1901.

(c) Cahiez, G.; Avedissian, H. Tetrahedron Lett. 1998, 39, 6159.

(d) Cahiez, G.; Marquais, S. Pure Appl. Chem. 1996, 68, 53.

[14] (a) Fürstner, A.; Leitner, A. Angew. Chem., Int. Ed. 2002, 41, 609.

(b) Fürstner, A.; Leitner, A.; Méndez, M.; Krause, H. J. Am. Chem. Soc. 2002, 124, 13856.

[15] (a) Fürstner, A.; Leitner, A. Angew. Chem., Int. Ed. 2003, 42, 308. (b) Fürstner, A.; Souza, D. D.; Rapado, L. P.; Jensen, J. T. Angew. Chem., Int. Ed. 2003, 42, 5358.

(c) Fürstner, A.; Turet, L. Angew. Chem., Int. Ed. 2005, 44, 3462.

[16] Scheiper, B.; Bonnekessel, M.; Krause, H.; Fürstner, A. J. Org. Chem. 2004, 69, 3949.

[17] Seidel, G.; Laurich, D.; Fürstner, A. J. Org. Chem. 2004, 69, 3950.

[18] (a) Jonas, K.; Schieferstein, L.; KrMger, C.; Tsay, Y.-H. Angew. Chem., Int. Ed. Engl. 1979, 18, 550.

(b) Jonas, K.; Schieferstein, L. Angew. Chem., Int. Ed. Engl. 1979, $18,549$.

[19] Hocek, M.; Dvořákova, H. J. Org. Chem. 2003, 68, 5773.

[20] Ottesen, L. K.; Fredrik, E. K.; Olsson, R. Org. Lett. 2006, 8, 1771.

[21] Nakamura, M.; Matsuo, K.; Ito, S.; Nakamura, E. J. Am. Chem. Soc. 2004, 126, 3686.

[22] Martin, R.; Fürstner, A. Angew. Chem., Int. Ed. 2004, 43, 3955.

[23] Cahiez, G.; Habiak, V.; Duplais, C.; Moyeux, A. Angew. Chem., Int. Ed. 2007, 46, 4364.

[24] Cahiez, G.; Duplais, C.; Moyeux, A. Org. Lett. 2007, 9. 325.

[25] Gurinot, A.; Reymond, S.; Cossy, J. Angew. Chem., Int. Ed. 2007, 46,6521 .

[26] Gurinot, A.; Lepesqueux, G.; Sable, S.; Reymond, S.; Cossy, J. J. Org. Chem. 2010, 75, 5151.

[27] (a) Bedford, R. B.; Bruce, D. W.; Frost, R. M.; Goodbyb, J. W.; Hirdb, M. Chem. Commun. 2004, 2822.

(b) Bedford, R. B.; Bruce, D. W.; Frost, R. M.; Hirdb, M. Chem. Commun. 2005, 4161.

[28] Chowdhury, R. R.; Crane, A. K.; Fowler, C.; Kwong, P.; Kozak, C. M. Chem. Commun. 2008, 94.

[29] Yamaguchi, Y.; Ando, H.; Nagaya, M.; Hinago, H.; Ito, T.; Asami, M. Chem. Lett. 2011, 40, 983.

[30] Bedford, R. B.; Betham, M.; Bruce, D. W.; Danopoulos, A. A.; Robert, M. F.; Michael, H. J. Org. Chem. 2006, 71, 1104.

[31] Bedford, R. B.; Huwea, M.; Wilkinson, M. C. Chem. Commun. 2009, 600 .

[32] Hatakeyama, T.; Kondo, Y.; Fujiwara, Y.-I.; Takaya, H.; Ito, S.; Nakamura, E.; Nakamura, M. Chem. Commun. 2009, 1216.

[33] (a) Tamura, M.; Kochi, J. J. Organomet. Chem. 1971, 31, 289. (b) Tamura, M.; Kochi, J. K. Bull. Chem. Soc. Jpn. 1971, 44, 3063.

[34] Adams, C. J.; Bedford, R. B.; Carter, E.; Gower, N. J.; Haddow, M. F.; Harvey, J. N.; Huwe, M.; Cartes, M. Á.; Mansell, S. M.; Mendoza, C.; Murphy, D. M.; Neeve, E. C.; Nunn, J. J. Am. Chem. Soc. 2012, 134, 10333.

[35] Bedford, R. B.; Carter, E.; Cogswell, P. M.; Gower, N. J.; Haddow, M. F.; Harvey, J. N.; Murphy, D. M.; Neeve, E. C.; Nunn, J. Angew. Chem., Int. Ed. 2013, 52, 1285.

[36] Jana, R.; Pathak, T. P.; Sigman, M. S. Chem. Rev. 2012, 111, 1417.

[37] (a) Hatakeyama, T.; Hashimoto, T.; Kondo, Y.; Fujiwara, Y.; Seike, H.; Takaya, H.; Tamada, Y.; Ono, T.; Nakamura, M. J. Am. Chem. Soc. 2010, 132, 10674.

(b) Hashimoto, T.; Hatakeyama, T.; Nakamura, M. J. Org. Chem. 2012, 77, 1168.

(c) Hatakeyama, T.; Hashimoto, T.; Kathriarachchi, K. K. A. D. S.; 
Zenmyo, T.; Seike, H.; Nakamura, M. Angew. Chem., Int. Ed. 2012, $124,1$.

(d) Nakagawa, N.; Hatakeyama, T.; Nakamura, M. Chem. Lett. 2015, 44, 486 .

[38] Bedford, R. B.; Brenner, P. B.; Carter, E.; Clifton, J.; Cogswell, P. M.; Gower, N. J.; Haddow, M. F.; Harvey, J. N.; Kehl, J. A.; Murphy, D. M.; Neeve, E. C.; Neidig, M. L.; Nunn, J.; Snyder, B. E. R.; Taylor, J. Organometallics 2014, 33, 5767.

[39] Nakamura, M.; Hirai, A.; Nakamura, E. J. Am. Chem. Soc. 2000, 122, 978 .

[40] Jin, M.; Adak, L.; Nakamura, M. J. Am. Chem. Soc. 2015, 137, 7128.

[41] Jin, M.; Nakamura, M. Chem. Lett. 2011, 40, 1012.

[42] Cahiez, G.; Marquais, S. Pure Appl. Chem. 1996, 68, $53 .$.

[43] (a) Sapountzis, I.; Lin, W. W.; Kofink, C. C.; Despotopoulou, C.; Knochel, P. Angew. Chem., Int. Ed. 2005, 44, 1654.

(b) Kofink, C. C.; Blank, B.; Pagano, S.; Gótz, N.; Knochel, P. Chem. Commun. 2007, 1954.

[44] (a) Hatakeyama, T.; Nakagawa, N.; Nakamura, M. Org. Lett. 2009, $11,4496$.

(b) Ito, S.; Fujiwara, Y.-I.; Nakamura, E.; Nakamura, M. Org. Lett. 2009, 11, 4306.

[45] Cahiez, G.; Habiak, V.; Gager, O. Org. Lett. 2008, 10, 2389.

[46] Li, B.-J.; Xu, L.; Wu, Z.-H.; Guan, B.-T.; Sun, C.-L.; Wang, B.-Q.; Shi, Z.-J. J. Am. Chem. Soc. 2009, 131, 14656.

[47] Agrawal, T.; Cook, S. P. Org. Lett. 2013, 15, 96.

[48] Itami, K.; Higashi, S.; Mineno, M.; Yoshida, J.-I. Org. Lett. 2005, 7, 1219.

[49] Denmark, S. E.; Cresswell, A. J. J. Org. Chem. 2013, 78, 12593.

[50] Chandra, M.; Volla, R.; Vogel, P. Angew. Chem., Int. Ed. 2008, 47, 1305.

[51] Dongol, K. G.; Koh, H.; Sau, M. and Chai, C. L. L. Adv. Synth. Catal. 2007, 349, 1015.

[52] Hatakeyama, T.; Hashimoto, T.; Kathriarachchi, K. K. A. D. S.; Zenmyo, T.; Seike, H.; Nakamura, M. Angew. Chem., Int. Ed. 2012, 51,8834 .

[53] Hatakeyama, T.; Yoshimoto, Y.; Gabriel, T.; Nakamura, M. Org. Lett. 2008, 10, 5341.

[54] Xie, X.; Xu, X. B.; Li, H. F.; Xu, X. L.; Yang, J. Y.; Lia, Y. Z. Adv. Synth. Catal. 2009, 351, 1263.

[55] Carril, M.; Correa, A.; Bolm, C. Angew. Chem., Int. Ed. 2008, 47, 4862.

[56] Mao, J. C.; Xie, G. L.; Wu, M. Y.; Guo, J.; Ji, S. J. Adv. Synth. Catal. 2008, 350, 2477.

[57] Chandra, M.; Volla, R.; Vogel, P. Tetrahedron Lett. 2008, 49, 5961.

[58] Hatakeyama, T.; Okada, Y.; Yoshimoto, Y.; Nakamura M. Angew. Chem., Int. Ed. 2011, 50, 10973.

[59] Nakagawa, N.; Hatakeyama, T.; Nakamura, M. Chem. Lett. 2015, $44,486$.

[60] Cheung, C. W.; Ren, P.; Hu, X. L. Org. Lett. 2014, 16, 2566.

[61] Quintin, J.; Franck, X.; Hocquemiller, R.; Figadère, B. Tetrahedron Lett. 2002, 43, 3547.

[62] Ludovic, B.; Mirca, D.; Alain, T.; Nelly, P. J. Heterocycl. Chem. 2005, 42, 1423.

[63] Kuzmina, O. M.; Steib, A. K.; Flubacher, D.; Knochel, P. Org. Lett. 2012, 14, 4818 .

[64] Kuzmina, O. M.; Steib, A. K.; Markiewicz, J. T.; Flubacher, D.; Knochel, P. Angew. Chem., Int. Ed. 2013, 52, 4945.

[65] Hatakeyama, T.; Nakamura, M. J. Am. Chem. Soc. 2007, 129, 9844.

[66] Hatakeyama, T.; Hashimoto, S.; Ishizuka, K.; Nakamura, M. J. Am. Chem. Soc. 2009, 131, 11949.

[67] Agrawal, T.; Cook, S. P. Org. Lett. 2014, 16, 5080.
[68] (a) Liu, C.; Zhang, H.; Shi, W.; Lei, A. W. Chem. Rev. 2011, 1780. (b) Shi, W.; Liu, C.; Lei, A. W. Chem. Soc. Rev. 2011, 40, 2761.

[69] Selected reviews:

(a) Littke, A. F.; Fu, G. C. Angew. Chem., Int. Ed. 2002, 41, 4176.

(b) Fu, G. C. Acc. Chem. Res. 2008, 41, 1555.

(c) Martin, R.; Buchwald, S. L. Acc. Chem. Res. 2008, 41, 1461.

(d) Marion, N.; Nolan, S. P. Acc. Chem. Res. 2008, 41, 1440.

(e) Fortman, G. C.; Nolan, S. P. Chem. Soc. Rev. 2011, 40, 5151.

[70] Selected reviews:

(a) Mulvey, R. E.; Mongin, F.; Uchiyama, M.; Kondo, Y. Angew. Chem., Int. Ed. 2007, 46, 3802.

(b) Haag, B.; Mosrin, M.; Ila, H.; Malakhov, V.; Knochel, P. Angew. Chem., Int. Ed. 2011, 50, 9794.

(c) Mongin, F.; Harrison-Marchand, A. Chem. Rev. 2013, 113, 7563.

(d) Klatt, T.; Markiewicz, J. T. Sämann, C.; Knochel, P. J. Org. Chem. 2014, 79, 4253.

[71] Nagano, T.; Hayashi, T. Org. Lett. 2005, 7, 491.

[72] Cahiez, G.; Chaboche, C.; Betzer, F. M.; Ahr, M. Org. Lett. 2005, 7, 1943.

[73] Cahiez, G.; Moyeux, A.; Buendia, J.; Duplais, C. J. Am. Chem. Soc. 2007, 129, 13788.

[74] Liu, W.; Lei, A. W. Tetrahedron Lett. 2008, 49, 610.

[75] Truong, T.; Alvarado, J.; Tran, L. D.; Daugulis, O. Org. Lett. 2010, $12,1200$.

[76] Cahiez, G.; Foulgoc, L.;Moyeux, A. Angew. Chem., Int. Ed. 2009, 48, 2969.

[77] Liu, K. M.; Liao, L. Y.; Duan, X. F. Chem. Commun. 2015, 51, 1124.

[78] Liu, K. M.; Wei, J.; Duan, X. F. Chem. Commun. 2015, 51, 4655.

[79] Xu, X. L.; Cheng, D. P.; Pei, W. J. Org. Chem. 2006, 71, 6637.

[80] Sridevi, V. S.; Leong, W. -K. Tetrahedron Lett. 2007, 48, 6669.

[81] Czaplik, W. M.; Mayer, M.; von Wangelin, A. J. ChemCatChem 2011, 3, 135

[82] For selected literatues on $\mathrm{Pd}$ catalyzed $\mathrm{C}-\mathrm{H}$ activation:

(a) Jia, C.; Piao, D.; Oyamada, J.; Lu, W.; Kitamura, T.; Fujiwara, Y. Science 2000, 287, 1992.

(b) Lyons, T. W.; Sanford, M. S. Chem. Rev. 2010, 110, 1147.

(c) Chen, X.; Engle, K. M.; Wang, D.-H.; Yu, J.-Q. Angew. Chem., Int. Ed. 2009, 48, 5094.

Ir catalyzed $\mathrm{C}-\mathrm{H}$ activation:

(d) Cho, J.-Y.; Tse, M. K.; Holmes, D. R.; Maleczka, E., Jr.; Smith, M. R., III Science 2002, 295, 305.

(e) Mkhalid, I. A. I.; Barnard, J. H.; Marder, T. B.; Murphy, J. M.; Hartwig, J. F. Chem. Rev. 2010, 110, 890.

$\mathrm{Ru}$ catalyzed $\mathrm{C}-\mathrm{H}$ activation:

(f) Ritleng, V.; Sirlin, C.; Pfeffer, M. Chem. Rev. 2002, 102, 1731.

(g) Colby, D. A.; Bergman, R. G.; Ellman, J. A. Chem. Rev. 2010, 110, 624. Pt catalyzed C-H activation:

(h) Lersch, M.; Tilset, M. Chem. Rev. 2005, 105, 2471.

(i) Yang, S.; Li, Z.; Jian, X.; He, C. Angew. Chem., Int. Ed. 2009, $48,3999$.

[83] Jones, W. D.; Foster, G. P.; Putinas, J. M. J. Am. Chem. Soc. 1987, 109, 5047

[84] Wen, J.; Zhang, J.; Chen, S.-Y.; Li, J.; Yu, X.-Q. Angew. Chem., Int. Ed. 2008, 47, 8897.

[85] Wen, J.; Qin, S.; Ma, L.-F.; Dong, L.; Zhang, J.; Liu, S.-S.; Duan, Y.-S.; Chen, S.-Y.; Hu, C.-W.; Yu X.-Q. Org. Lett. 2010, 12, 2694.

[86] Deb, A.; Manna, S.; Maji, A.; Dutta, U.; Maiti, D. Eur. J. Org. Chem. 2013, 5251.

[87] Liu, W.; Cao, H.; Lei, A. W. Angew. Chem., Int. Ed. 2010, 49, 2004.

[88] Vallée, F.; Mousseau, J. J.; Charette, A. J. Am. Chem. Soc. 2010, 
$132,1514$.

[89] Norinder, J.; Matsumoto, A.; Yoshikai, N.; Nakamura, E. J. Am. Chem. Soc. 2008, 130, 5858 .

[90] Yoshikai, N.; Matsumoto, A.; Norinder, J.; Nakamura, E. Angew. Chem., Int. Ed. 2009, 48, 2925.

[91] Yoshikai, N.; Matsumoto, A.; Norinder, J.; Nakamura, E. Synlett $2010,313$.

[92] Yoshikai, N.; Asako, S.; Yamakawa, T.; Ilies, L.; Nakamura, E. Chem. Asian J. 2011, 6, 3059.

[93] Ilies, L.; Kobayashi, M.; Matsumoto, A.; Yoshikai, N.; Nakamura, E. Adv. Synth. Catal. 2012, 354, 593.

[94] Shang, R.; Ilies, L.; Matsumoto, A.; Nakamura, E. J. Am. Chem. Soc. 2013, 135, 6030.

[95] Shang, R.; Ilies, L.; Nakamura, E. J. Am. Chem. Soc. 2015, 137, 7660 .

[96] Shang, R.; Ilies, L.; Nakamura, E. J. Am. Chem. Soc. 2016, 138, 10132.

[97] Li, Z. P.; Cao, L.; Li, C.-J. Angew. Chem., Int. Ed. 2007, 46, 6505.

[98] Li, Y.-Z;. Li, B.-J.; Lu, X.-Y.; Lin, S.; Shi, Z.-J. Angew. Chem., Int. Ed. 2009, 48,1 .

[99] Zhang, Y.; Li, C.-J. Eur. J. Org. Chem. 2007, 4654.

[100] Li, Z. P.; Yu, R.; Li, H. J. Angew. Chem., Int. Ed. 2008, 47, 7497.

[101] Li, H.; He, Z.; Guo, X.; Li, W.; Zhao, X.; Li, Z. Org. Lett. 2009, 11, 4176.

[102] Liu, P.; Wang, Z. M.; Lin, J.; Hu, X. M. Eur. J. Org. Chem. 2012, 1583.

[103] For Selected literatures on the synthesis of amino acid derivatives: (a) Beak, P.; Zajdel, W. J.; Reitz, D. B. Chem. Rev. 1984, 84, 471.

(b) Knowles, H. S.; Hunt, K.; Parsons, A. F. Tetrahedron Lett.
2000, 41, 7121.

(c) Burger, K.; Geith, K.; Gaa, K. Angew. Chem., Int. Ed. Engl. 1988, 27, 848.

(d) Ireland, R. E.; Mueller, R. H. Willard, A. K. J. Am. Chem. Soc. 1976, 98, 2868;

[104] Yoshikai, N.; Mieczkowski, A.; Matsumoto, A.; Ilies, L.; Nakamura, E. J. Am. Chem. Soc. 2010, 132, 5568

[105] Qian, B.; Xie, P.; Xie, Y. J.; Huang, H. M. Org. Lett. 2011, 13, 2580.

[106] Volla, C. M. R.; Vogel, P. Org. Lett. 2009, 11, 1701.

[107] Chandrasekharam, M.; Chiranjeevi, B. P.; Gupta, K. S. V.; Sridhar, B. J. Org. Chem. 2011, 76, 10229.

[108] Guo, X.; Yu, R.; Li, H.; Li, Z. J. Am. Chem. Soc. 2009, 131,17387.

[109] For recent reviews, see:

(a) Davies, H. M. L.; Manning, J. R. Nature 2008, 451, 417.

(b) Giri, R.; Shi, B. F.; Engle, K. M.; Maugel, N.; Yu, J.-Q. Chem. Soc. Rev. 2009, 38, 3242.

(c) Doyle, M. P.; Duffy, R.; Ratnikov, M.; Zhou, L. Chem. Rev. 2010, 110, 704.

[110] Zhu, S.-F.; Zhou, Q.-L. Natl. Sci. Rev. 2014, 1, 580.

[111] Li, Y.; Huang, J.-S.; Zhou, Z.-Y.; Che, C.-M.; You, X.-Z. J. Am. Chem. Soc. 2002, 124,13185.

[112] Mbuvi, H. M.; Woo, L. K. Organometallics 2008, 27, 637.

[113] Cai, Y.; Zhou, S.-F.; Wang, G.-P.; Zhou, Q.-L. Adv. Synth. Catal. 2011, 353, 2939.

[114] Yang, J.-M.; Cai, Y.; Zhu, S.-F.; Zhou, Q.-L. Org. Biomol. Chem. 2016, 14, 5516.

(Qin, X.) 